\title{
Rhizobacterial communities of five co-occurring desert halophytes
}

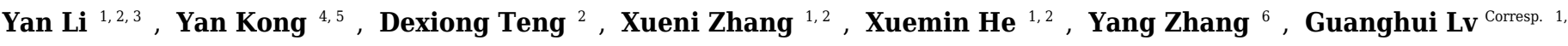 \\ ${ }^{1}$ Key Laboratory of Oasis Ecology of Education Ministry, Xinjiang University, Urumqi, Xinjiang, China \\ 2 Institute of Arid Ecology and Environment, Xinjiang University, Urumqi, Xinjiang, China \\ 3 Ecology Post-doctoral Research Station, Xinjiang University, Urumqi, Xinjiang, China \\ 4 School of Life Science and Biotechnology, Shanghai Jiaotong University, Shanghai, China \\ 5 SJTU-Yale Joint Center for Biostistics, Shanghai Jiaotong University, Shanghai, China \\ ${ }^{6}$ College of Resource and Environment Sciences, Xinjiang University, Urumqi, Xinjiang, China \\ Corresponding Author: Guanghui Lv \\ Email address: ler@xju.edu.cn
}

Background: Recently, researches have begun to investigate the microbial communities associated with halophytes. Both rhizobacterial community composition and the environmental drivers of community assembly have been addressed. However, few studies have explored the structure of rhizobacterial communities associated with halophytic plants that are co-occurring in arid, salinized areas. Methods: Five halophytes were selected for study: these co-occurred in saline soils in the Ebinur Lake Nature Reserve, located at the western margin of the Gurbantunggut Desert of Northwestern China. Halophyte-associated bacterial communities were sampled, and the bacterial 16S rDNA V3-V4 region amplified and sequenced using the Illumina Miseq platform. The bacterial community diversity and structure were compared between the rhizosphere and bulk soils, as well as among the rhizosphere samples. The effects of plant species identity and soil properties on the bacterial communities were also analyzed. Results: Significant differences were observed between the rhizosphere and bulk soil bacterial communities. Diversity was higher in the rhizosphere than in the bulk soils. Abundant taxonomic groups (from phylum to genus) in the rhizosphere were much more diverse than in bulk soils. Proteobacteria, Firmicutes, Actinobacteria, Bacteroidetes and Planctomycetes were the most abundant phyla in the rhizosphere, while Proteobacteria and Firmicutes were common in bulk soils. Overall, the bacterial community composition were not significantly differentiated between the bulk soils of the five plants, but community diversity and structure differed significantly in the rhizosphere. The diversity of Halostachys caspica, Halocnemum strobilaceum and Kalidium foliatum associated communities was lower than that of Limonium gmelinii and Lycium ruthenicum communities. Furthermore, the composition of Halostachys caspica and Halocnemum strobilaceum communities was very 
different from that of Limonium gmelinii and Lycium ruthenicum communities. The diversity and community structure were influenced by soil EC, $\mathrm{pH}$ and nutrient content (TOC, SOM, TON and AP); of these, the effects of EC on bacterial community composition were less important than those of soil nutrients. DISCUSSION: Halophytic plant species played an important role in shaping associated rhizosphere bacterial communities. When salinity levels were constant, soil nutrients emerged as key factors structuring bacterial communities, while EC played only a minor role. Pairwise differences among the rhizobacterial communities associated with different plant species were not significant, despite some evidence of differentiation. Further studies involving more halophyte species, and individuals per species, are necessary to elucidate plant species identity effects on the rhizosphere for co-occurring halophytes. 
1

\section{Rhizobacterial communities of five co-occurring desert}

\section{3 halophytes}

4

5 Yan LI 1, 2,3, Yan Kong ${ }^{4,5}$, Dexiong Teng ${ }^{2}$, Xueni Zhang ${ }^{1,2}$, Xuemin HE ${ }^{1,2}$,

6 Yang Zhang ${ }^{6}$, Guanghui Lv ${ }^{1,2, *}$

7

81 Key Laboratory of Oasis Ecology, Education Ministry, Urumqi, China

92 Institute of Arid Ecology and Environment, Xinjiang University, Urumqi, China

103 Ecology Post-doctoral Research Station, Xinjiang University, Urumqi, China

114 School of Life Science and Biotechnology, Shanghai Jiaotong University, Shanghai, China

125 SJTU-Yale Joint Center for Biostistics, Shanghai Jiaotong University, Shanghai, China

136 College of Resource and Environment Sciences, Xinjiang University, Xinjiang, China

* Corresponding author, email: ler@xju.edu.cn 
ABSTRACT

Background: Recently, researches have begun to investigate the microbial communities associated with have been addressed. However, few studies have explored the structure of rhizobacterial communities associated with halophytic plants that are co-occurring in arid, salinized areas.

Methods: Five halophytes were selected for study: these co-occurred in saline soils in the Ebinur Lake Nature associated bacterial communities were sampled, and the bacterial 16S rDNA V3-V4 region amplified and sequenced using the Illumina Miseq platform. The bacterial community diversity and structure were compared between the rhizosphere and bulk soils, as well as among the rhizosphere samples. The effects of plant species identity and soil properties on the bacterial communities were also analyzed.

Results: Significant differences were observed between the rhizosphere and bulk soil bacterial communities. Diversity was higher in the rhizosphere than in the bulk soils. Abundant taxonomic groups (from phylum to genus) in the rhizosphere were much more diverse than in bulk soils. Proteobacteria, Firmicutes, Actinobacteria, Bacteroidetes and Planctomycetes were the most abundant phyla in the rhizosphere, while Proteobacteria and Firmicutes were common in bulk soils. Overall, the bacterial community composition were not significantly differentiated between the bulk soils of the five plants, but community diversity and structure differed significantly in the rhizosphere. The diversity of Halostachys caspica, Halocnemum strobilaceum and Kalidium foliatum associated communities was lower than that of Limonium gmelinii and Lycium ruthenicum communities. Furthermore, the composition of Halostachys caspica and Halocnemum strobilaceum communities was very different from that of Limonium gmelinii and Lycium ruthenicum communities. The diversity and community structure were influenced by soil EC, pH and nutrient content (TOC, SOM, TON and AP); of these, the effects of EC on bacterial community composition were less important than those of soil nutrients.

DISCUSSION: Halophytic plant species played an important role in shaping associated rhizosphere bacterial communities. When salinity levels were constant, soil nutrients emerged as key factors structuring bacterial communities, while EC played only a minor role. Pairwise differences among the rhizobacterial communities associated with different plant species were not significant, despite some evidence of differentiation. Further studies involving more halophyte species, and individuals per species, are necessary to elucidate plant species identity effects on the rhizosphere for co-occurring halophytes. 


\section{INTRODUCTION}

Salinization is a serious land degradation problem, as high salinity limits plant growth. Salts may accumulate in soils as a result of natural processes, such as mineral weathering, dust collection and precipitation, or artificial processes, such as irrigation (Oosterbaan 1988); both may lead to saline soils that make it difficult for plants to absorb moisture from the soil. Halophytes are salt-tolerant plants that can grow in areas with salt $(\mathrm{NaCl})$ concentrations higher than $400 \mathrm{mM}$ (Flowers 2004; English \& Colmer 2011). In saline soil environments, halophytes play an important role in carbon sequestration, nutrient mineralization, nutrient cycling and improvement of the micro-environment (Cao et al. 2014; Chaudhary et al. 2015), and may have great potential to preserve ecosystems.

Salinity tolerance in halophytes is not solely due to physiological mechanisms and their genetic regulation (Vasquez et al. 2005), but also to complex ecological processes within the plant rhizosphere and phyllosphere; microorganisms inhabiting the roots and leaves of halophytes may significantly contribute to their salinity tolerance (Ruppel et al. 2013). Many microorganisms have plant growth-promoting activities and confer salt tolerance on halophytic plants (Nabti et al. 2007; Sgroy et al. 2009; Jha et al. 2012; Mapelli et al. 2013). Recent studies of halophyte-associated microbial communities have addressed the ecological and environmental drivers underlying community assembly and recruitment (Jha et al. 2012; Borruso et al. 2014; Marasco et al. 2016; Chaudhary et al. 2017; Tian \& Zhang 2017). These studies have revealed that bacterial communities in the halophyte rhizosphere are distinctly different from those of non-halophytic plants, containing a larger proportion of halophilic bacteria (Al-Mailem et al. 2010). Many halophilic bacteria have been identified or isolated from halophyte roots, soils and desert habitats, including species belonging to the following genera: Alkalimonas, Bacillus, Brachybacterium, Brevibacterium, Cronobacter, Halobacillus, Halomonas, Marinococcus, Methylibium, Nesterenkonia, Oceanobacillus, Staphylococcus, Stenotrophomonas, Virgibacillus and Zhihengliuella (Sgroy et al. 2009; Siddikee et al. 2010; Tang et al. 2011; Shi et al. 2012; Zhou et al. 2012; Ramadoss et al. 2013; Borsodi et al. 2015; Zhao et al. 2016).

The diversity and composition of the rhizosphere bacterial community depends not only on the plant species, but also on various soil parameters (Tian \& Gao 2014; Rodriguez-Blanco et al. 2015; Pii et al. 2016; Song et al. 2017). Different plant species, or even genotypes within species, tend to assemble distinct rhizobacterial communities (Chaudhary et al. 2015). For example, in the rhizosphere of Aster tripolium, Actinobacteria, Firmicutes and Proteobacteria are the most abundant bacterial phyla, and Bacillus the dominant genus (Szymanska et al. 2016b). In contrast, Acidimicrobiales, Myxococcales and Sphingomonadales are common in the rhizosphere of Halimione portulacoides and Sarcocornia perennis (Oliveira et al. 2014). The Puccinellia limosa rhizosphere is dominated by Halomonas and Nesterenkonia species (Borsodi et al. 2015). Similar rhizobacterial communities may be found in different environments when the same plant species is present (Smalla et al. 2001; Berg \& Smalla 2009). However, in certain environments, such as hypersaline soils, plant species identity plays only a minor role compared to soil salinity in shaping microbial community structure (Borruso et al. 2014); this result has been confirmed by studies of desert soils (Li et al. 2013). Overall, both plant species identity and soil type can be important, depending on abiotic and biotic conditions (Berg \& Smalla 2009).

While many studies have investigated the effects of plant species identity and various soil properties, as well as other factors (i.e. temperature, geographical distance), on structuring microbial communities in the rhizosphere, few studies have characterized the rhizobacterial communities associated with halophytic plants found in arid, saline environments. In a Mediterranean salt marsh in Southeastern Spain, a study of eight 
halophytes (Asteriscus maritimus, Arthrocnenium macrostachyum, Frankenia corymbosa, Halimione portulacoides, Limonium cossonianum, Limonium caesium, Lygeum spartum and Suaeda vera Forsskal) examined the soil microbiological and biochemical properties of the rhizosphere, revealing that soil microbial activity and microbial-related soil properties, such as aggregate stability, were determined by the plant species. However, the community composition of the microbes was not examined (Caravaca et al. 2005). Another study recently compared the microbial communities associated with three dominant halophytes (Aeluropus, Salicornia and Suaeda) in a coastal region of India (Chaudhary et al. 2015). To date, in halophytic species occurring in arid desert environments, little is known regarding rhizobacterial community assembly and the relative contributions of rhizosphere effects versus salinity to this process.

In this study, the bacterial communities associated with five halophytes (Halocnemum strobilaceum, Halostachys caspica, Limonium gmelinii, Lycium ruthenicum and Kalidium foliatum) growing in arid, saline environments were characterized. The diversity and structure of rhizosphere bacterial communities was investigated using an Illumina MiSeq sequencing approach. The study goals were to: 1) compare the bacterial communities of the rhizosphere with those found in bulk soil samples (i.e. non-rhizosphere samples), in order to understand the effects of plant species identity on bacterial communities; 2) compare the rhizosphere community composition of the five halophytic species so as to look for similarities across species; and, 3) evaluate the relative contributions of plant species identity and soil salinity in structuring rhizosphere bacterial communities in arid, saline habitats.

\section{MATERIALS \& METHODS}

\section{Study area and sample collection}

Soil samples were collected from the Ebinur Lake Wetland, Xinjiang, China $\left(44.595^{\circ} \mathrm{N}, 83.552^{\circ} \mathrm{E}\right)$ in July 2017 , following previously established protocols (Chaudhary et al. 2015; Edwards et al. 2015). The Ebinur Lake Nature Reserve is located at the western margin of the Gurbantunggut Desert in Xinjiang, China. Conditions are windy in the Reserve, which has a typical dry, continental climate, with an annual average precipitation of $105 \mathrm{~mm}$ and evaporation of $1315 \mathrm{~mm}$. Soils in the Reserve are highly salinized and alkalized, with an average electrical conductivity (EC) of $5.41 \mathrm{mS} / \mathrm{cm}$ and $\mathrm{pH}$ of 8.77 in surface soils $0-10 \mathrm{~cm}$ deep; the mean soil water content is 7.19\% (Zhang et al. 2014). As such, many halophytic species grow in this region. In this study, five co-occurring halophytic plants species, four shrubs (Halocnemum strobilaceum, Halostachys caspica, Lycium ruthenicum and Kalidium foliatum, ) and one perennial herb (Limonium gmelinii), were selected for study.

Thirty samples were collected in total: 15 from the rhizosphere and 15 paired bulk soil samples. Each rhizosphere sample came from a different plant; sampled individuals were distributed within a $1 \mathrm{~km}$ radius of the GPS coordinates provided above (Fig S1). Three healthy individuals were randomly selected from each species to be sampled. Plant roots were dug up using a shovel, in order to collect all roots to a depth of approximately $35-45 \mathrm{~cm}$. Excess soil was manually shaken from the roots, but any soil still attached after shaking (a layer $\sim 1 \mathrm{~mm}$ thick) was retained for study. Each root sample was immediately placed into a sterile flask with $30 \mathrm{ml}$ of sterile Phosphate Buffered Saline (PBS) solution $(137 \mathrm{mmol} / \mathrm{L} \mathrm{NaCl}, 2.7 \mathrm{mmol} / \mathrm{L} \mathrm{KCl}, 8.5$ $\mathrm{mmol} / \mathrm{LNa}_{2} \mathrm{HPO}_{4}, 1.5 \mathrm{mmol} / \mathrm{L} \mathrm{KH}_{2} \mathrm{PO}_{4}, \mathrm{pH}$ 7.3). Bulk soil samples were collected from sites $30-40 \mathrm{~cm}$ away from the roots of a given plant; soils were collected to a depth of approximately $40 \mathrm{~cm}$. About $100 \mathrm{~g}$ of fresh soil from each sample was stored in a sterile plastic bag; these were immediately transported back to the lab on ice. In the lab, the flasks containing root samples were stirred vigorously with sterile forceps to clean all the soil from the root surfaces. This soil was then poured into a $50 \mathrm{ml}$ sterile Falcon tube ready for DNA extraction. 
131

132

133

134

135

136

137

138

139

140

141

142

143

144

145

146

147

148

149

150

151

152

153

154

155

156

157

158

159

160

161

162

163

164

165

166

167

168

169

170

171

\section{Soil chemical analysis}

Soil samples were dried in a hot air oven at $105^{\circ} \mathrm{C}$ for 48 hours to determine the soil water content (SWC). After drying, samples were ground and sieved through $2 \mathrm{~mm}$ mesh. The electrical conductivity (EC) and $\mathrm{pH}$ were measured in a 1:2.5 (w:v) soil to water mix. The total organic carbon (TOC) and soil organic matter (SOM) were estimated using a spectrophotometer, after oxidizing soil samples with $\mathrm{K}_{2} \mathrm{Cr}_{2} \mathrm{O}_{4}$ (Yang 1987). The total nitrogen (TON) was determined using the Kjeldahl method (Honda 1962). To measure available phosphorus (AP), samples were digested with $\mathrm{HClO}_{4}-\mathrm{H}_{2} \mathrm{SO}_{4}$, and then the Mo-Sb colorimetric method was used for quantification (Agrochemistry Committee of the Chinese Soil Society 1983).

\section{DNA extraction, amplification and sequencing}

Rhizosphere samples were concentrated by pipetting $1 \mathrm{~mL}$ of the PBS/soil mix into a $2 \mathrm{~mL}$ sterile tube and centrifuging for $1 \mathrm{~min}$ at $10,000 \mathrm{~g}$. The supernatant was discarded leaving only the soil fraction behind. About $0.2 \mathrm{~g}$ of soil (wet weight) from each bulk sample was transferred to a $2 \mathrm{~mL}$ sterile tube. Then, the total genomic DNA was extracted using an E.Z.N.A ${ }^{\mathrm{TM}}$ Mag-Bind Soil DNA Kit (OMEGA) following the manufacturer's instructions. DNA samples were inspected on a $1.0 \%$ agarose gel and quantified using a Nanodrop 2000 spectrophotometer (Nanodrop Technologies, Wilmington DE). The bacterial 16S rDNA V3-V4 region was amplified and sequenced for analysis. PCR products were visualized using electrophoresis on $1.5 \%$ agarose gels and purified using VAHTS ${ }^{\mathrm{TM}}$ DNA Clean Beads (Vazyme, Nanjing, China). Finally, about $10 \mathrm{ng}$ of DNA from each sample was sequenced on the Illumina MiSeq platform by Sangon Technology Co., Ltd. (Shanghai, China). The sequence data has been submitted to the NCBI Sequence Read Archive database under accession number SRP129060.

\section{Sequence preprocessing and OTU assignment}

Quality control of raw sequencing data was conducted following Schmieder \& Edwards (Schmieder \& Edwards 2011). Ambiguous bases with Phred quality score $<20$ at the end of a read and fragments containing Ns were trimmed. Reads with length $<200$ nucleotides (nt) were removed, and the remaining reads truncated to 400-450 nt sequences. Chimeric sequences were identified with UCHIME (Edgar et al. 2011) and discarded (109-1397 chimeras per sample). The filtered sequences were then clustered into OTUs at a $97 \%$ similarity level. A representative sequence from each OTU was selected for both taxonomic annotation using the Ribosomal Database Project (RDP) classifier (Wang et al. 2007) and also to BLAST against the Silva and NCBI databases (Quast et al. 2013). OTUs with an RDP classification threshold below 0.8 or with identity and coverage lower than $90 \%$ were marked as unclassified. Singletons and sequences aligning to the mitochondria or chloroplast were removed (4-1450 reads per sample). Finally, the number of sequences in each sample was normalized by random resampling to the smallest sample size $(\mathrm{n}=35000)$ prior to calculation of species diversity indices (Shannon, Simpson, Chao1, ACE, and Good's coverage) using Mothur ver 1.30.1 (Schloss et al. 2009). OTU richness was calculated using the vegan package ver. 2.1-10 (Dixon 2003) in R ver. 3.2. Rarefaction analysis was implemented in Mothur 1.30.1 and a rarefaction curve produced in R. Using R, a species accumulation curve was also constructed (with the vegan package) and diagrams depicting bacterial community structure (composition and relative abundance) at multiple taxonomic ranks (phylum, class, order, family and genus) were generated.

\section{Statistical analysis}

One-way ANOVAs were used to test for differences in alpha diversity indices (OTU richness, Shannon diversity index and Good's coverage index) as well as soil physicochemical properties. A principal coordinates analysis 
172 (PCoA) was performed on weighted UniFrac distances (using the vegan package) to compare community

173

174

175

176

177

178

179

180

181

182

composition among samples. A UPGMA tree depicting clustering relationships among samples was produced based on Bray-Curtis beta diversity distance metrics. ANOSIM (999 permutations) and Adonis statistics, available in the vegan package, were calculated to evaluate differences in rhizosphere community composition among the five study species. Venn diagrams illustrating similarities/differences in OTU composition between samples were produced with the Venn-Diagram package, ver. 1.6.16. Furthermore, STAMP 2.1.3 (Parks et al. 2014) and LEfSe 1.1.0 (Segata et al. 2011) were implemented to identify differentially abundant groups among samples. Pearson's correlation coefficients were calculated between the community diversity and richness indices and each soil property, and also among soil properties. Correspondence analysis (CA) was performed using the vegan package to investigate links between community structure, soil properties and plant species.

\section{RESULTS}

\section{Soil properties}

The average soil water content (SWC) of bulk soils was $16.40 \pm 4.57 \%$. The electrical conductance (EC) was $6.30 \pm 1.21 \mathrm{mS} / \mathrm{cm}$ and $\mathrm{pH} 8.14 \pm 0.27$. The mean total organic carbon (TOC), soil organic matter (SOM), total nitrogen (TON) and available phosphorus (AP) were $8.05 \pm 4.15 \mathrm{~g} / \mathrm{kg}, 13.87 \pm 7.15 \mathrm{~g} / \mathrm{kg}, 0.48 \pm 0.23 \mathrm{~g} / \mathrm{kg}$ and $0.82 \pm 0.14 \mathrm{~g} / \mathrm{kg}$, respectively. Halocnemum strobilaceum and Halostachys caspica soils had higher EC and lower TOC, SOM and TON compared to those of other species $(P<0.05)$. The AP content in Halocnemum strobilaceum soils was significantly lower than for other species $(P<0.05)$ (Table 1$)$.

\section{Bacterial community diversity}

In total, $1.83 \mathrm{~Gb}$ of raw sequence data was obtained from all samples; after quality controls, a total of $1.18 \mathrm{~Gb}$ of clean sequence reads were available for further analysis. Good's coverage for all samples was higher than 0.98 (Table S1). Rarefaction curves stabilized as the number of sequences increased (Fig. S2), suggesting that bacterial communities were reasonably well-characterized. Species accumulation curves nearly reached a plateau, where the number of OTUs did not increase with sample size, indicating that the sample size was sufficient for data analysis (Fig. S3). After removal of chimeras, plant sequences and singletons, a total of 1315341 reads were obtained from soil samples; these were grouped into 8087 OTUs. OTU richness was higher in rhizosphere versus bulk soil samples $(P<0.01$; Fig. 1). The number of OTUs identified in the rhizosphere of each species ranged from a minimum of 2342 (for Halocnemum strobilaceum) to a maximum of 4602 (Limonium gmelinii); within species, the number of OTUs present in all three replicates ranged from 317 to 729 . In bulk soil samples, the number of OTUs detected for each species ranged from 1108 to 3688, and between 94 and 220 OTUs were common to all three replicates within species (Table S1).

Bacterial community diversity was higher in the rhizosphere versus bulk soil samples (ANOVA $P<0.01$ ) (Fig. 1). Rhizobacterial diversity did not differ among Halocnemum strobilaceum, Halostachys caspica and Kalidium foliatum, but was lower in these species than in Limonium gmelinii and Lycium ruthenicum $(P<0.05)$. Diversity in Lycium ruthenicum bulk soil samples was higher than in the other four plant species $(P<0.05)$. There were 1005, 1001, 677, 589 and 510 OTUs exclusive to the rhizobacterial communities associated with Halostachys caspica, Limonium gmelinii, Lycium ruthenicum, Kalidium foliatum, and Halocnemum strobilaceum, respectively; of these, 135, 187, 242, 88 and 63 OTUs, respectively, were found in all withinspecies replicates. Comparing across species, 242 OTUs were identified in all bulk soil samples and 647 OTUs in all rhizosphere samples; only 31 and 87 of these OTUs, respectively, were found in all three individuals of each species (Fig. 2). Abundant OTUs (i.e., those accounting for $>0.1 \%$ of sequences) common to the 
213

214

215

216

217

218

219

220

221

222

223

224

225

226

227

228

229

230

231

232

233

234

235

236

237

238

239

240

241

242

243

244

245

246

247

248

249

250

251

252

253

rhizospheres of all halophytes belonged to 16 genera, including Acinetobacter, Aliifodinibius, Citrobacter, Deferrisoma, Exiguobacterium, Gracilimonas, Halomonas, Marinobacter, Pseudomonas, Thioprofundum and others. Considering bulk soils, the most abundant OTUs came from four genera: Acinetobacter, Citrobacter, Exiguobacterium and Pseudomonas (Fig. S4).

\section{Bacterial community structure}

A total of 36 phyla, 61 classes, 201 families and 617 genera were identified over all samples. In the bulk soil samples, Proteobacteria and Firmicutes were the dominant phyla. Gammaproteobacteria and Bacilli were the dominant classes, and Acinetobacter, Bacillus, Citrobacter, Exiguobacterium and Pseudomonas were the most abundant genera (Fig. 3). In the rhizosphere samples, Acidobacteria, Actinobacteria, Bacteroidetes, Chloroflexi, Firmicutes,Planctomycetes, Proteobacteriaand Verrucomicrobia were the most abundant phyla. Actinobacteria, Bacilli, Cytophagia, Flavobacteriia, Planctomycetia, Sphingobacteriia, Alphaproteobacteria, Deltaproteobacteria and Gammaproteobacteriawere the most abundant classes. The most common genera included Acinetobacter, Aliifodinibius, Citrobacter, Deferrisoma, Exiguobacterium, Geminicoccus, Gp10, Gracilimonas, Halomonas, Marinobacter, Pseudomonas and Thioprofundum (Fig. 3).

\section{Differences between rhizosphere and bulk soil samples}

The most abundant bacterial groups in bulk soil communities were less common in rhizosphere communities, whereas some low abundance groups in the former were more common in the latter. At the phylum level, the Firmicutes and Proteobacteria was relatively less abundant in the rhizosphere, especially in the case of Firmicutes $(P<0.001)$, whereas the Acidobacteria, Actinobacteria, Bacteroidetes, Chloroflexi, Planctomycetes and Verrucomicrobia were more abundant. A similar pattern was also observed at lower taxonomic ranks; however, overall, there were more abundant groups in the rhizosphere. Comparing bulk soil, the following genera were lower in abundance: Acinetobacter, Citrobacter, Exiguobacterium, Halomonas and Pseudomonas. Meanwhile, Aciditerrimonas, Aliifodinibius, Deferrisoma, Fodinicurvata, Geminicoccus, Gp10, Gracilimonas, Marinobacter, Nitriliruptor, Planococcus and Thioprofundum were more abundant in the rhizosphere samples $(P<0.01)$ (Fig. 3).

Community composition differed significantly between rhizosphere and bulk soil samples (ANOSIM, $\mathrm{R}=$ $0.961, P=0.001)$. A PCoA analysis illustrates these differences in community structure (Fig. 4a). Rhizosphere and bulk soil samples are separated on the first PCoA axis, which explained $82.33 \%$ of the variance. Bulk soil samples clustered together, indicating a high degree of similarity among their bacterial communities. However, rhizosphere samples were less tightly aggregated than bulk soil samples. Consistent with the PCoA results, the UPGMA tree also distinguished rhizosphere communities from bulk soil communities (Fig. 4b).

\section{Community structure differences among the five halophytes}

Significant variation in community structure was observed among the five species' rhizospheres $\left(\mathrm{R}^{2}=0.703, P\right.$ $=0.001$ ). However, pairwise differences between each species pair, though relatively large, were not significant $(P>0.05)$ (Table 2). The rhizobacterial community of Lycium ruthenicum was most similar to that of Limonium gmelinii. Meanwhile, the Halocnemum strobilaceum rhizobacterial community was most dissimilar to those of other species. As determined by a LEfSe analysis, rhizobacterial community composition differed among the five halophytes (Fig. 5). The genera Gimesia and Pelagibius were significantly more abundant in the Lycium ruthenicum rhizosphere; Albidovulum, Bauldia, Deferrisoma, Geminicoccus, Gp10 and Thiohalomonas were more common in the Limonium gmelinii rhizosphere, Citrobacter, Exiguobacteriumand Pseudomonas in the Halostachys caspica rhizosphere, Gracilimonas, Jiangella, Marinimicrobium, Planococcus andPontibacter in 
254

255

256

257

258

259

260

261

262

263

264

265

266

267

268

269

270

271

272

273

274

275

276

277

278

279

280

281

282

283

284

285

286

287

288

289

290

291

292

293

the Kalidium foliatum rhizosphere, and Fodinicurvata, Halomonas, Mesorhizobium and Salegentibacter in the Halocnemum strobilaceum rhizosphere.

In contrast, an Adonis analysis found no differences in community composition among bulk soil samples from different species $\left(\mathrm{R}^{2}=0.300, P=0.413\right)$. However, LEfSe analyses found differences in composition in bulk soil communities for four out of the five species (Fig. 6). The bacterial community associated with Lycium ruthenicum was relatively distinct from that of other species, mainly due to differences in the abundance of the following families: Acidimicrobiaceae, Anaerolineaceae, Alteromonadaceae, Bacillaceae, Chromatiaceae, Demequinaceae, Planctomycetaceae, Puniceicoccaceae, Rhodobiaceae and Sprospiraceae, . Meanwhile, Kalidium foliatum communities were indistinguishable from those of the other four species.

\section{Correlations between bacterial diversity, community structure and soil properties}

Relationships between microbial community diversity and structure, and soil bio-chemical properties were assessed with Pearson correlation coefficients and canonical correspondence analysis (CCA). The soil TOC, TON and AP were all strongly positively correlated, while EC was negatively correlated with all other soil variables except $\mathrm{pH}$. Bacterial community diversity and richness were positively correlated with soil TON and AP, but negatively correlated with EC (Table 3) The first canonical axis (CCA1) was negatively correlated with EC, while the second canonical axis (CCA2) was positively correlated with SWC, but negatively correlated with EC. The SWC, TOC, SOM, TON and AP were more important in determining the bacterial community composition (as represented by longer arrows) than $\mathrm{pH}$ and $\mathrm{EC}$, indicating that $\mathrm{EC}$ played only a minor role in the shaping of community structure. Rhizosphere communities from Lycium ruthenicum and Limonium gmelinii samples were positively associated with higher SWC, TON and AP. Meanwhile, Halostachys caspica rhizosphere communities were positively correlated with EC, and Halocnemum strobilaceum communities negatively correlated (Fig. 7a). Considering the bulk soil samples, CCA1 was positively correlated with EC and negatively correlated with the TOC, TON and $\mathrm{pH}$. The second axis (CCA2) was positively correlated with AP and SWC. Apart from Lycium ruthenicum, the other species' samples were negatively correlated with SOM, TON and AP, but positively correlated with EC. The TON, AP and $\mathrm{pH}$ had a stronger influence on community structure than SOM or EC (Fig. 7b).

\section{DISCUSSION}

\section{Bacterial community structure in saline soils as compared to other environments}

Soil salinity has important effects on the distribution of plant communities, their composition and diversity (Xi et al. 2016), and may also affect soil bacterial diversity and community structure (Fang et al. 2016; Pavloudi et al. 2016). Plant communities in salinized habitats are dominated by halophytes, and the abundance and diversity of associated microbial communities, in saline or hypersaline terrestrial environments, is usually low (Takekawa et al. 2006; Jiang et al. 2007; Foti et al. 2008). In this study, bacterial communities were very low in richness and diversity compared to documented communities in forests, grasslands and agricultural areas (Rampelotto et al. 2013), maize crop soils (Garcia-Salamanca et al. 2013) and even other saline soils (Canfora et al. 2014); however, metrics were consistent with those found in other "extreme" hypersaline soils in semiarid Mediterranean regions (Canfora et al. 2015). The soils surrounding Halocnemum strobilaceum had the lowest diversity and richness, perhaps as a result of the relatively high soil EC and low nutrient availability. Soils associated with Lycium ruthenicum were the most diverse of all studied plant species. Considering that nutrient availability in Lycium ruthenicum-associated soils was only mediocre, other factors (i.e., plant community 
294

295

296

297

298

299

300

301

302

303

304

305

306

307

308

309

310

311

312

313

314

315

316

317

318

319

320

321

322

323

324

325

326

327

328

329

330

331

332

333

334

composition) likely affected the soil bacterial community (Ravit et al. 2003; Cao et al. 2014). Indeed, based on field observations, the plant community surrounding focal Lycium ruthenicum individuals was more diverse and had higher percent cover than for other species.

Bulk soil samples had similar, relatively simple bacterial communities. Only four genera, Acinetobacter, Citrobacter, Exiguobacterium and Pseudomonas, were common, which differs from the bacterial communities of saline soils in Inner Mongolia (Borruso et al. 2014) and the Shandong Peninsula coast (Tian \& Zhang 2017). Differences in community composition may be due to distinct climatic and/or soil properties among geographic regions (Ben-David et al. 2011). However, the dominance of Bacilli (Firmicutes) and $\gamma$-proteobacteria in the study region is consistent with previous studies (Tang et al. 2011; Borsodi et al. 2013), confirming that these two taxa are important in saline or hypersaline environments. A low level of structural differentiation was also found when comparing communities associated with different plant species, as determined by a LEfSe analysis. The highest differentiation was observed between Lycium ruthenicum and the other species; in contrast, Kalidium foliatum communities were indistinguishable from those of other species. This suggests that soil bacterial communities are highly similar in arid environments, at least on a small geographic scale. Microhabitat similarities may produce such similar bacterial communities, as low plant cover and a lack of plant litter are common to arid environments.

\section{Bacterial community composition in the rhizosphere versus bulk soils}

Rhizosphere effects may be an important driving force shaping microbial communities and leading to compositional differences between the rhizosphere and the bulk soils (Morgan \& Whipps 2001). In this study, bacterial communities differed between the rhizosphere and bulk soils, with higher community diversity and richness in the rhizosphere, consistent with previous studies (Avis et al. 2008; Borruso et al. 2014; Edwards et al. 2015; Chaudhary et al. 2017; Yang et al. 2017). Higher diversity may be a result of root exudates, which can raise nutrient concentrations ( $\mathrm{Li}$ et al. 2014). While soil properties were not measured exhaustively here, the soil TOC and TON contents estimated in the rhizosphere of Limonium gmelinii and Lycium ruthenicum were approximately 5-7 times higher than in the bulk soils. However, it should be noted that bulk soils may have greater microbial richness than the rhizosphere in some cases (Shange et al. 2012; Carbonetto et al. 2014; Gomes et al. 2014; Tian \& Zhang 2017). These divergent results suggest that the soil type and plant species identity have complex effects on bacterial communities, with the strength of their effects depending on abiotic and biotic conditions (Berg \& Smalla 2009).

In addition to diversity differences, the composition of bacterial communities also differed between the rhizosphere and bulk soil samples, as revealed by PCoA and cluster analysis. Compared to bulk soils, the rhizosphere communities had more groups with relative abundance $>1 \%$, such as the following phyla:Actinobacteria, Bacteroidetes, Firmicutes, Planctomycetes and Proteobacteria. Dominance by a greater number of groups has also been reported in other saline ecosystems, both marine and terrestrial (Tang et al. 2011; Marasco et al. 2013; Oliveira et al. 2014; Soussi et al. 2016). At the genus level, many genera were abundant in the rhizosphere, for example Acinetobacter, Bacillus, Citrobacter, Deferrisoma, Exiguobacterium, Haliea, Halomonas, Marinimicrobium, Marinobacter, Methylohalomonas, Microbulbifer, Planococcus, Pseudomonas and Thioprofundum (Fig. 3, Fig. S5). Meanwhile, the richness of groups common in bulk soils (i.e. $\gamma$ proteobacteria and Firmicutes) was reduced in the rhizosphere; for example, the abundance of Firmicutes was about $80 \%$ lower. The low abundance of Firmicutes in the rhizosphere has been reported many times; see one such case study in barley, where Firmicutes is almost excluded from the rhizosphere (Bulgarelli et al. 2015). 
335

336

337

338

339

340

341

342

Although $\gamma$-proteobacteria were less abundant in the rhizosphere, as observed by a decrease in the number of occurrences of Acinetobacter, Citrobacter and Pseudomonas species, $\gamma$-proteobacteria remained the most abundant class, as found in many plant-associated bacterial communities (Mukhtar et al. 2017).

Shifts in bacterial community composition in bulk soils versus the rhizosphere may be the consequence of active selection by plants (Kowalchuk et al. 2002). As many endophytes and bacteria colonizing root surfaces have beneficial effects, such as nitrogen fixation, phytohormone production, nutrient supply and pathogen suppression (Rosenblueth \& Martinez-Romero 2006; Hardoim et al. 2008), they typically promote plant growth and can alleviate salt stress in halophytes (Ali et al. 2015). Some Microbulbifer and Planococcus species have the ability to degrade complex hydrocarbons (See-Too et al. 2017). Meanwhile, Bacillus, Exiguobacterium, Halomonas, Planococcus and Pseudomonascan generate 1-aminocyclopropane-1- carboxylic acid (ACC) deaminase to convert the ethylene precursor ACC into ammonia and $\alpha$-ketobutyrate; this has the effect of lowering the ethylene concentration within plant tissues, reducing its constraining effect on root elongation and general plant growth (Siddikee et al. 2010). Moreover, some Bacillus, Halomonas and Pseudomonas species in can produce indole-3-acetic acid (IAA) to confer salt tolerance (Tiwari et al. 2011). Halomonas species are able to tolerate a wide set of abiotic stresses, and promote plant growth via IAA production, phosphate solubilization, nitrogen fixation and more (Mapelli et al. 2013). In rhizobacterial communities, Bacillus and Pseudomonas species are critically important for plant growth; these species have multiple functional activities, including phosphate solubilization, phytopathogen inhibition (Prashar et al. 2014) and auxin production. Why these species are less abundant in the rhizosphere (versus bulk soils) remains unclear. It could be caused by competition among rhizobacteria, but this hypothesis needs verification. Moreover, the effects of many other common genera in the rhizosphere (whether beneficial, harmful or neutral), as well their inter-relationships (mutualistic or competitive) with plant growth promoting species, need further investigation.

\section{Differences among halophytes in rhizobacterial communities and relationship to soil properties}

A number of studies have demonstrated that microbial community composition is plant species specific (Andreote et al. 2009; Poli et al. 2016), leading to unique rhizobacterial communities among species. Here, five halophyte-associated rhizobacterial communities varied both in diversity (ANOVA $P<0.01$ ) and structure (Adonis $\mathrm{R}^{2}=0.703, P=0.001$ ). Rhizobacterial diversity was lower in Halostachys caspica, Halocnemum strobilaceum and Kalidium foliatum than in Limonium gmelinii and Lycium ruthenicum $(P<0.05)$. While community composition also seemed to vary, differences were not significant (Table 2). Halomonas was the dominant genera in Halocnemum strobilaceum communities (32.4\% of total abundance), a significantly higher proportion than in the other plant-associated communities; this trend is consistent with previous studies (AlMailem et al. 2010; Marasco et al. 2016), including of other halophytes (Borsodi et al. 2015). In the Halostachys caspica rhizosphere, Exiguobacterium was the most common genus, followed by Citrobacter, Acinetobacter and Pseudomonas. Meanwhile, in the Kalidium foliatum rhizosphere, Halomonas, Exiguobacterium and Gracilimonas were most abundant. The rhizobacterial communities of Limonium gmelinii and Lycium ruthenicum were highly similar (Adonis $\mathrm{R}^{2}=0.324, P=0.108$ ), perhaps as a result of similar soil properties. The relatively high abundance of Exiguobacterium in the rhizosphere is unique to this study, suggesting that it is potentially important in the study region, but this requires furtherinvestigation.

Furthermore, among replicates for a given plant species, only a small proportion of OTUs occurred in all three. Interestingly, these shared OTUs were usually highly abundant overall, whereas OTUs that were found only in one or two individuals were mostly rare OTUs (with a relative abundance less than five). Thus, bacterial 
communities may have individual specificity, potentially influenced by a plant's genotype, age or health (Zhu et al. 2013; Belimov et al. 2015). The OTUs found across all five plant species belong to 16 genera in total, and some, such as Deferrisoma, Exiguobacterium, Geminicoccus, Gracilimonas and Marinimicrobium, were also included in the taxa identified in the LEfSe. As successful colonizers of halophyte plants in saline-arid lands, these may be good plant growth promotion rhizobacteria (PGPR) candidates.

Soil properties are also important determinants of soil microbial communities (Szymanska et al. 2016a; Rathore et al. 2017). In particular, soil salinity is considered a primary environmental factor, directly or indirectly driving the composition and diversity of prokaryotic communities (Marasco et al. 2016; Zhong et al. 2016). In this study, soil EC had a positive influences on the bulk soil bacterial communities, and other soil factors also shaped bacterial community composition. Soil nutrients (TON, TOC and AP) were most important for Lycium ruthenicum. Similarly, a recent study found that variation in prokaryotic community structure was significantly correlated with the TON and $\mathrm{PO}_{4}{ }^{3-}$ concentration (Zhong et al. 2016). In the rhizosphere, EC was negatively correlated with rhizobacterial community diversity and structure, though its influence on community structure was only minor as revealed by the CCA. In contrast, the effects of soil nutrients, such as TOC, SOM, TON and $\mathrm{AP}$, were much stronger than those of $\mathrm{EC}$ or soil $\mathrm{pH}$. The low diversity and compositional variation seen in Halostachys caspica and Halocnemum strobilaceum rhizobacterial communities were negatively correlated with soil TOC, SOM, TON and AP. These results imply that, when salinity levels are similar among habitats, the influence of salinity on the rhizosphere microbial community structure is relatively weak. In these cases, rhizobacterial community structure is more strongly influenced by the host plant identity and soil nutrient content, whereas salinity has a minor effect.

Overall, variation in rhizobacterial community structure among the five study plant species was significant, though pairwise differences did not reach significance despite the large number of OTUs that were unique to each species. This may be explained by the relatively low total abundance of rare OTUs, as well as the low proportion of shared OTUs in a given plant species. While abundant OTUs were shared across all five plant species (and accounted for a large proportion of total richness in each), they differed in relative abundance. This suggests that, in similar saline habitats, plants tend to select similar bacterial species to colonize roots, perhaps as a consequence of adaptation to salinity stress; these species may act to promote plant growth or alleviate salt stress. Coevolution between microorganisms and associated plant species has been addressed in leguminous Rhizobium species (Wang et al. 2018). Community differences (especially in the richness of abundant groups) may be closely related to differences in root exudates or plant litter between plant species (Chaudhary et al. 2015), as supported by the results here. However, the effects of other factors, such as ion concentration, and interactions between microbiomes within a community (Chen et al. 2013; Poosakkannu et al. 2017) cannot be excluded.

\section{CONCLUSIONS}

The present study investigated the composition and diversity of rhizobacterial communities in five cooccurring halophytic species growing in salinized, arid desert soils within the Ebinur Lake Wetland Reserve in Northwestern China. Significant differences were found between the rhizosphere and bulk soil communities, both in diversity and bacterial composition. Diversity was higher in the rhizosphere than in the bulk soils. Abundant taxonomic groups (from phylum to genus) in the rhizosphere were much more diverse than in bulk soils. Actinobacteria, Bacteroidetes, Firmicutes, Planctomycetes and Proteobacteria were the most abundant 
416 phyla in the rhizosphere, while Firmicutes and Proteobacteria were common in bulk soils. Comparing among

417 species, significant differences in rhizobacterial diversity and identity were observed. The diversity of 418 Halostachys caspica, Halocnemum strobilaceum and Kalidium foliatum associated communities was lower than 419 that of Limonium gmelinii and Lycium ruthenicum communities. Furthermore, the composition of Halostachys 420 caspica and Halocnemum strobilaceum communities was very different from that of Limonium gmelinii and 421 Lycium ruthenicum communities. Thus, plant species identity can have important effects on root-associated 422 bacterial communities. Diversity was positively correlated with soil nutrients, including TOC, SOM, TON and 423 AP, but negatively correlated with EC, though the effects of EC were much lower than those of soil nutrient 424 content. In conclusion, halophytic plant species played an important role in shaping associated rhizosphere 425 bacterial communities. Furthermore, when salinity levels were constant, soil nutrients emerged as key factors 426 structuring bacterial communities. These results provide insight into the nature of halophyte microbial 427 communities in arid regions, as well as the factors shaping these communities. However, pairwise differences 428 among the five rhizobacterial communities were not significant, despite some evidence for differentiation among 429 plant species. Further studies involving more halophyte species and individuals per species are necessary to 430 elucidate plant species identity effects on the rhizosphere for co-occurring halophytes.

431

432

\section{ACKNOWLEDGMENTS}

434

435

436

437

438

439

440

441

442

443

444

445

446

447

448

449

450

451

452

453

454

455

We would like to thank LetPub, Elizabeth Tokarz at the Yale University and Dr. Emily Drummond at the University of British Columbia for their assistance with English language and grammatical editing of the manuscript. We would also like to thank Dr. Rodrigo Taketani and the anonymous reviewers for their comments and suggestions that improved the quality of our manuscript.

\section{ADDITIONAL INFORMATION AND DECLARATIONS}

Fig. S1 Collection locations of soil samples used in the present study.

Fig. S2 Rarefaction curves for bacterial OTUs, clustering at 97\% sequence similarity. Error bars indicate standard errors.

Fig. S3 Species accumulation curves for soil samples. The horizontal bars within boxes represent the medians, while the tops and bottoms of the boxes represent 75 th and 25 th quartiles, respectively. Plus signs $(+)$ indicate outliers.

Fig. S4 Phylogeny and taxonomic classification of abundant OTUs shared among either rhizosphere or bulk soil communities.

Fig. S5 Relative abundance of common phyla and genera in bulk soil and rhizosphere bacterial communities.

Table S1 Alpha diversity indices of bacterial communities in rhizosphere and bulk soil samples.

\section{TABLE CAPTIONS}

Table 1 Soil characteristics of bulk soil samples from five halophytes.

Table 2 Adonis analysis of bacterial community composition for bulk soil and rhizosphere samples.

Table 3 Pearson correlation coefficients among soil chemical properties, and between soil properties and 
456

457

458

459

460

461

462

463

464

465

466

467

468

469

470

471

472

473

474

475

476

477

478

479

480

481

482

483

484

485

486

487

488

489

490

491

492

493

494

495

496

community diversity.

\section{FIGURE LEGENDS}

Fig. 1 Multiple comparisons of OTU richness (a) and $\alpha$-diversity (Shannon's index) (b) between rhizospheric and bulk soil bacterial communities, and among plant species within soil type. Within boxes, horizontal bars indicate medians, while the tops and bottoms of boxes illustrate 75 th and 25 th quartiles, respectively. Small circles represent outliers in bulk samples. G, B, J, S, Z indicate bulk soil samples from Lycium ruthenicum, Limonium gmelinii, Halocnemum strobilaceum, Halostachys caspica, and Kalidium foliatum, respectively, while GQ, BX, JM, SM and ZZ denote the corresponding rhizosphere samples from each species. Significance levels ( $\mathrm{p}$ values) are provided for among-species comparisons within soil type (bulk versus rhizosphere), as well as between soil types.

Fig. 2 Venn diagram showing the OTUs shared among different samples. a: rhizosphere samples, b: bulk soil samples. Information on OTU numbers is provided as follows: the total number of OTUs detected across all three replicates for each species (the number of OTUs shared among the three replicates).

Fig. 3 Diagrams depicting community composition and relative abundance at different taxonomic levels. a: phylum, b: class, and c: genus.

Fig. 4 Principal coordinate analysis (PCoA) (a) and UPGMA clustering diagram (b) of soil samples. G, B, J, S and $\mathrm{Z}$ represent bulk soil samples from Lycium ruthenicum, Limonium gmelinii, Halocnemum strobilaceum, Halostachys caspica and Kalidium foliatum, respectively, while GQ, BX, JM, SM and ZZ represent rhizosphere samples associated with these species.

Fig. 5 LEfSe analysis at multiple taxonomic levels comparing rhizobacterial community composition for five focal plant species. (a) Cladogram illustrating the taxonomic groups explaining the most variation among rhizobacterial communities. Each ring represents a taxonomic level, with phylum (p), class (c), order (o), family (f) and genus (g) emanating from the center to the periphery. Each circle is a taxonomic unit found in the dataset, with circles or nodes shown in colors (other than yellow) indicating where a taxon was significantly more abundant. (b) Histogram of the LDA scores computed for groups with differential abundance among the rhizobacterial communities of the five plant species.

Fig. 6 LEfSe analysis of bacterial community composition for bulk soil samples from four plant species. (a) Cladogram illustrating the taxonomic groups that explain the most variation among the bacterial communities. (b) Histogram of the LDA scores computed for groups with differential abundance among the bacterial communities of the four plant species. Kalidium foliatum-associated communities did not form a separate group (from other plant species' associated communities) and, therefore, these are absent from the cladogram and histogram. 
497 Fig. 7 Canonical correspondence analysis (CCA) of the effect of soil properties on bacterial community structure 498 in the rhizosphere (a) and bulk soil samples (b). The soil properties are indicated with arrows, and include soil $499 \mathrm{pH}$, electrical conductivity (EC), total organic carbon (TOC), soil organic matter (SOM), total nitrogen (TON), 500 phosphorous (AP) and soil water content (SWC). The percentage of variation explained by each axis is provided. 501 GQ, BX, JM, SM and ZZ represent rhizosphere samples associated with Lycium ruthenicum, Limonium gmelinii, 502 Halocnemum strobilaceum, Halostachys caspica and Kalidium foliatum, respectively. G, B, J, S and Z represent 503 bulk soil samples from Lycium ruthenicum, Limonium gmelinii, Halocnemum strobilaceum, Halostachys 504 caspica and Kalidium foliatum, respectively.

505

506

507

508 
510

511

512

513

514

515

516

517

518

519

520

521

522

523

524

525

526

527

528

529

530

531

532

533

534

535

536

537

538

539

540

541

542

543

544

545

546

547

548

549

550

\section{REFERENCES}

Agrochemistry Committee of the Chinese Soil Society. 1983. Conventional analytical methods for soil agrochemistry. Beijing: Science Press.

Al-Mailem DM, Sorkhoh NA, Marafie M, Al-Awadhi H, Eliyas M, and Radwan SS. 2010. Oil phytoremediation potential of hypersaline coasts of the Arabian Gulf using rhizosphere technology. Bioresource Technology 101:5786-5792. 10.1016/j.biortech.2010.02.082

Ali Z, Ullah N, Naseem S, Inam-Ul-Haq M, and Jacobsen HJ. 2015. Soil bacteria conferred a positive relationship and improved salt stress tolerance in transgenic pea (Pisum sativum L.) harboring $\mathrm{Na}+\mathrm{H}+$ antiporter. Turkish Journal of Botany 39:962-+. 10.3906/bot-1505-50

Andreote FD, Rossetto PB, Mendes R, Avila LA, Labate CA, Pizzirani-Kleiner AA, Azevedo JL, and Araujo WL. 2009. Bacterial community in the rhizosphere and rhizoplane of wild type and transgenic eucalyptus. World Journal of Microbiology \& Biotechnology 25:1065-1073. 10.1007/s1 1274-0099990-9

Avis TJ, Gravel V, Antoun H, and Tweddell RJ. 2008. Multifaceted beneficial effects of rhizosphere microorganisms on plant health and productivity. Soil Biology \& Biochemistry 40:1733-1740. 10.1016/j.soilbio.2008.02.013

Belimov AA, Puhalsky IV, Safronova VI, Shaposhnikov AI, Vishnyakova MA, Semenova EV, Zinovkina NY, Makarova NM, Wenzel W, and Tikhonovich IA. 2015. Role of plant genotype and soil conditions in symbiotic plant-microbe interactions for adaptation of plants to Cadmium-polluted soils. Water Air and Soil Pollution 226. Artn 26410.1007/S1 1270-015-2537-9

Ben-David EA, Zaady E, Sher Y, and Nejidat A. 2011. Assessment of the spatial distribution of soil microbial communities in patchy arid and semi-arid landscapes of the Negev Desert using combined PLFA and DGGE analyses. Fems Microbiology Ecology 76:492-503. 10.1111/j.1574-6941.2011.01075.x

Berg G, and Smalla K. 2009. Plant species and soil type cooperatively shape the structure and function of microbial communities in the rhizosphere. Fems Microbiology Ecology 68:1-13. 10.1111/j.15746941.2009.00654.x

Borruso L, Bacci G, Mengoni A, De Philippis R, and Brusetti L. 2014. Rhizosphere effect and salinity competing to shape microbial communities in Phragmites australis (Cav.) Trin. ex-Steud. Fems Microbiology Letters 359:193-200. 10.1111/1574-6968.12565

Borsodi AK, Barany A, Krett G, Marialigeti K, and Szili-Kovacs T. 2015. Diversity and ecological tolerance of bacteria isolated from the rhizosphere of halophyton plants living nearby Kiskunsag soda ponds, Hungary. Acta Microbiologica Et Immunologica Hungarica 62:183-197. 10.1556/030.62.2015.2.8

Borsodi AK, Felfoldi T, Mathe I, Bognar V, Knab M, Krett G, Jurecska L, Toth EM, and Marialigeti K. 2013. Phylogenetic diversity of bacterial and archaeal communities inhabiting the saline Lake Red located in Sovata, Romania. Extremophiles 17:87-98. 10.1007/s00792-012-0496-2

Bulgarelli D, Garrido-Oter R, Munch PC, Weiman A, Droge J, Pan Y, McHardy AC, and Schulze-Lefert P. 2015. Structure and function of the bacterial root microbiota in wild and domesticated barley. Cell Host \& Microbe 17:392-403. 10.1016/j.chom.2015.01.011

Canfora L, Bacci G, Pinzari F, Lo Papa G, Dazzi C, and Benedetti A. 2014. Salinity and bacterial diversity: to what extent does the concentration of salt affect the bacterial community in a saline soil? Plos One 9:e106662. 10.1371/journal.pone.0106662 
551

552

553

554

555

556

557

558

559

560

561

562

563

564

565

566

567

568

569

570

571

572

573

574

575

576

577

578

579

580

581

582

583

584

585

586

587

588

589

590

591

Canfora L, Lo Papa G, Antisari LV, Bazan G, Dazzi C, and Benedetti A. 2015. Spatial microbial community structure and biodiversity analysis in "extreme" hypersaline soils of a semiarid Mediterranean area. Applied Soil Ecology 93:120-129. 10.1016/j.apsoil.2015.04.014

Cao D, Shi FC, Koike T, Lu ZH, and Sun JK. 2014. Halophyte plant communities affecting enzyme activity and microbes in saline soils of the Yellow River delta in China. Clean-Soil Air Water 42:1433-1440. 10.1002/clen.201300007

Caravaca F, Aiguacil MM, Torres P, and Roldan A. 2005. Plant type mediates rhizospheric microbial activities and soil aggregation in a semiarid Mediterranean salt marsh. Geoderma 124:375-382. 10.1016/j/geoderma.2004.05.010

Carbonetto B, Rascovan N, Alvarez R, Mentaberry A, and Vazquez MP. 2014. Structure, Composition and metagenomic profile of soil microbiomes associated to agricultural land use and tillage systems in Argentine pampas. Plos One 9. ARTN e9994910.1371/journal.pone.0099949

Chaudhary DR, Gautam RK, Yousuf B, Mishra A, and Jha B. 2015. Nutrients, microbial community structure and functional gene abundance of rhizosphere and bulk soils of halophytes. Applied Soil Ecology 91:16-26. 10.1016/j.apsoil.2015.02.003

Chaudhary DR, Rathore AP, Kumar R, and Jha B. 2017. Spatial and halophyte-associated microbial communities in intertidal coastal region of India. International Journal of Phytoremediation 19:478489. 10.1080/15226514.2016.1244168

Chen YL, Chen BD, Hu YJ, Li T, Zhang X, Hao ZP, and Wang YS. 2013. Direct and indirect influence of arbuscular mycorrhizal fungi on abundance and community structure of ammonia oxidizing bacteria and archaea in soil microcosms. Pedobiologia 56:205-212. 10.1016/j.pedobi.2013.07.003

Dixon P. 2003. VEGAN, a package of R functions for community ecology. Journal of Vegetation Science 14:927-930. DOI 10.1111/j.1654-1103.2003.tb02228.x

Edgar RC, Haas BJ, Clemente JC, Quince C, and Knight R. 2011. UCHIME improves sensitivity and speed of chimera detection. Bioinformatics 27:2194-2200. 10.1093/bioinformatics/btr381

Edwards J, Johnson C, Santos-Medellin C, Lurie E, Podishetty NK, Bhatnagar S, Eisen JA, and Sundaresan V. 2015. Structure, variation, and assembly of the root-associated microbiomes of rice. Proceedings of the National Academy of Sciences of the United States of America 112:E911-E920. 10.1073/pnas.1414592112

English JP, and Colmer TD. 2011. Salinity and waterlogging tolerances in three stem-succulent halophytes (Tecticornia species) from the margins of ephemeral salt lakes. Plant and Soil 348:379-396. 10.1007/s11104-011-0924-6

Fang TT, Pan RS, Jiang J, He F, and Wang H. 2016. Effect of salinity on community structure and naphthalene dioxygenase gene diversity of a halophilic bacterial consortium. Frontiers of Environmental Science \& Engineering 10. ARTN 1610.1007/s11783-016-0888-0

Flowers TJ. 2004. Improving crop salt tolerance. Journal of Experimental Botany 55:307-319. $10.1093 / \mathrm{j} x \mathrm{~b} / \mathrm{erh} 003$

Foti MJ, Sorokin DY, Zacharova EE, Pimenov NV, Kuenen JG, and Muyzer G. 2008. Bacterial diversity and activity along a salinity gradient in soda lakes of the Kulunda Steppe (Altai, Russia). Extremophiles 12:133-145. 10.1007/s00792-007-0117-7

Garcia-Salamanca A, Molina-Henares MA, van Dillewijn P, Solano J, Pizarro-Tobias P, Roca A, Duque E, 
592

593

594

595

596

597

598

599

600

601

602

603

604

605

606

607

608

609

610

611

612

613

614

615

616

617

618

619

620

621

622

623

624

625

626

627

628

629

630

631

632

and Ramos JL. 2013. Bacterial diversity in the rhizosphere of maize and the surrounding carbonaterich bulk soil. Microbial Biotechnology 6:36-44. 10.1111/j.1751-7915.2012.00358.x

Gomes NCM, Cleary DFR, Pires ACC, Almeida A, Cunha A, Mendonca-Hagler LCS, and Smalla K. 2014. Assessing variation in bacterial, composition between the rhizospheres of two mangrove tree species. Estuarine Coastal and Shelf Science 139:40-45. 10.1016/j.ecss.2013.12.022

Hardoim PR, van Overbeek LS, and van Elsas JD. 2008. Properties of bacterial endophytes and their proposed role in plant growth. Trends in Microbiology 16:463-471. 10.1016/j.tim.2008.07.008

Honda C. 1962. Rapid procedure for determination of nitrogen in soil by kjeldahl method. J Sci Soil Manure 33:195-200.

Jha B, Gontia I, and Hartmann A. 2012. The roots of the halophyte Salicornia brachiata are a source of new halotolerant diazotrophic bacteria with plant growth-promoting potential. Plant and Soil 356:265-277. 10.1007/s11104-011-0877-9

Jiang HC, Dong HL, Yu BS, Liu XQ, Li YL, Ji SS, and Zhang CLL. 2007. Microbial response to salinity change in Lake Chaka, a hypersaline lake on Tibetan plateau. Environmental Microbiology 9:26032621. 10.1111/j.1462-2920.2007.01377.x

Kowalchuk GA, Buma DS, de Boer W, Klinkhamer PGL, and van Veen JA. 2002. Effects of above-ground plant species composition and diversity on the diversity of soil-borne microorganisms. Antonie Van Leeuwenhoek International Journal of General and Molecular Microbiology 81:509-520. Doi 10.1023/A: 1020565523615

Li K, Liu RY, Zhang HX, and Yun JL. 2013. The diversity and abundance of bacteria and oxygenic phototrophs in saline biological desert crusts in Xinjiang, Northwest China. Microbial Ecology 66:4048. 10.1007/s00248-012-0164-1

Li XZ, Rui JP, Mao YJ, Yannarell A, and Mackie R. 2014. Dynamics of the bacterial community structure in the rhizosphere of a maize cultivar. Soil Biology \& Biochemistry 68:392-401. 10.1016/j.soilbio.2013.10.017

Mapelli F, Marasco R, Rolli E, Barbato M, Cherif H, Guesmi A, Ouzari I, Daffonchio D, and Borin S. 2013. Potential for plant growth promotion of rhizobacteria associated with salicornia growing in Tunisian hypersaline soils. Biomed Research International. Artn 24807810.1155/2013/248078

Marasco R, Mapelli F, Rolli E, Mosqueira MJ, Fusi M, Bariselli P, Reddy M, Cherif A, Tsiamis G, Borin S, and Daffonchio D. 2016. Salicornia strobilacea (synonym of Halocnemum strobilaceum) grown under different tidal regimes selects rhizosphere bacteria capable of promoting plant growth. Frontiers in Microbiology 7. ARTN 128610.3389/fmicb.2016.01286

Marasco R, Rolli E, Fusi M, Cherif A, Abou-Hadid A, El-Bahairy U, Borin S, Sorlini C, and Daffonchio D. 2013. Plant growth promotion potential is equally represented in diverse grapevine root-associated bacterial communities from different biopedoclimatic environments. Biomed Research International. Artn 49109110.1155/2013/491091

Morgan JAW, and Whipps JM. 2001. Methodological approaches to the study of rhizosphere carbon flow and microbial population dynamics. In: Pinton A, Varanini Z, Nannipieri P (eds) The rhizosphere: biochemistry and organic substances at the soil-plant interface Marcel Dekker, New York,:373-409.

Mukhtar S, Ishaq A, Hassan S, Mehnad S, Mirza MS, and Malik KA. 2017. Comparison of microbial communities associated with halophyte (Salsola stocksii) and non-halophyte (Triticum aestivum)

PeerJ reviewing PDF | (2018:02:25925:2:1:NEW 24 Jul 2018) 
633

634

635

636

637

638

639

640

641

642

643

644

645

646

647

648

649

650

651

652

653

654

655

656

657

658

659

660

661

662

663

664

665

666

667

668

669

670

671

672

673

using culture-independent approaches. Polish Journal of Microbiology 66:353-364.

Nabti E, Sahnoune M, Adirad S, Van Dommelen A, Ghoul M, Schmid M, and Hartmann A. 2007. A halophilic and osmotolerant Azospirillum brasilense strain from Algerian soil restores wheat growth under saline conditions. Engineering in Life Sciences 7:354-360. 10.1002/elsc.200720201

Oliveira V, Gomes NCM, Cleary DFR, Almeida A, Silva AMS, Simoes MMQ, Silva H, and Cunha A. 2014. Halophyte plant colonization as a driver of the composition of bacterial communities in salt marshes chronically exposed to oil hydrocarbons. Fems Microbiology Ecology 90:647-662. 10.1111/15746941.12425

Oosterbaan RJ. 1988. Effectiveness and social/environmental impacts of irrigation projects: a criticial review. In ILRI Annual Report 1988, international institute for land reclamation and improvement,. Wageningen, The Netherlands:18-34.

Parks DH, Tyson GW, Hugenholtz P, and Beiko RG. 2014. STAMP: statistical analysis of taxonomic and functional profiles. Bioinformatics 30:3123-3124. 10.1093/bioinformatics/btu494

Pavloudi C, Oulas A, Vasileiadou K, Sarropoulou E, Kotoulas G, and Arvanitidis C. 2016. Salinity is the major factor influencing the sediment bacterial communities in a Mediterranean lagoonal complex (Amvrakikos Gulf, Ionian Sea). Marine Genomics 28:71-81. 10.1016/j.margen.2016.01.005

Pii Y, Borruso L, Brusetti L, Crecchio C, Cesco S, and Mimmo T. 2016. The interaction between iron nutrition, plant species and soil type shapes the rhizosphere microbiome. Plant Physiology and Biochemistry 99:39-48. 10.1016/j.plaphy.2015.12.002

Poli A, Lazzari A, Prigione V, Voyron S, Spadaro D, and Varese GC. 2016. Influence of plant genotype on the cultivable fungi associated to tomato rhizosphere and roots in different soils. Fungal Biology 120:862872. 10.1016/j.funbio.2016.03.008

Poosakkannu A, Nissinen R, and Kytoviita MM. 2017. Native arbuscular mycorrhizal symbiosis alters foliar bacterial community composition. Mycorrhiza 27:801-810. 10.1007/s00572-017-0796-6

Prashar P, Kapoor N, and Sachdeva S. 2014. Rhizosphere: its structure, bacterial diversity and significance. Reviews in Environmental Science and Bio-Technology 13:63-77. 10.1007/s11157-013-9317-z

Quast C, Pruesse E, Yilmaz P, Gerken J, Schweer T, Yarza P, Peplies J, and Glockner FO. 2013. The SILVA ribosomal RNA gene database project: improved data processing and web-based tools. Nucleic Acids Research 41:D590-D596. 10.1093/nar/gks1219

Ramadoss D, Lakkineni VK, Bose P, Ali S, and Annapurna K. 2013. Mitigation of salt stress in wheat seedlings by halotolerant bacteria isolated from saline habitats. Springerplus 2. Artn 610.1186/21931801-2-6

Rampelotto PH, Ferreira AD, Barboza ADM, and Roesch LFW. 2013. Changes in diversity, abundance, and structure of soil bacterial communities in Brazilian Savanna under different land use systems. Microbial Ecology 66:593-607. 10.1007/s00248-013-0235-y

Rathore AP, Chaudhary DR, and Jha B. 2017. Seasonal patterns of microbial community structure and enzyme activities in coastal saline soils of perennial halophytes. Land Degradation \& Development 28:17791790. 10.1002/ldr.2710

Ravit B, Ehrenfeld JG, and Haggblom MM. 2003. A comparison of sediment microbial communities associated with Phragmites australis and Spartina alterniflora in two brackish wetlands of New Jersey. Estuaries 26:465-474. Doi 10.1007/Bf02823723 
674

675

676

677

678

679

680

681

682

683

684

685

686

687

688

689

690

691

692

693

694

695

696

697

698

699

700

701

702

703

704

705

706

707

708

709

710

711

712

713

714

Rodriguez-Blanco A, Sicardi M, and Frioni L. 2015. Plant genotype and nitrogen fertilization effects on abundance and diversity of diazotrophic bacteria associated with maize (Zea mays L.). Biology and Fertility of Soils 51:391-402. 10.1007/s00374-014-0986-8

Rosenblueth M, and Martinez-Romero E. 2006. Bacterial endophytes and their interactions with hosts. Molecular Plant-Microbe Interactions 19:827-837. 10.1094/Mpmi-19-0827

Ruppel S, Franken p, and Witzel K. 2013. Properties of the halophyte microbiome and their implications for plant salt tolerance. Functional Plant Biology 40:940-951.

Schloss PD, Westcott SL, Ryabin T, Hall JR, Hartmann M, Hollister EB, Lesniewski RA, Oakley BB, Parks DH, Robinson CJ, Sahl JW, Stres B, Thallinger GG, Van Horn DJ, and Weber CF. 2009. Introducing mothur: open-source, platform-independent, community-supported software for describing and comparing microbial communities. Applied and Environmental Microbiology 75:7537-7541. 10.1128/Aem.01541-09

Schmieder R, and Edwards R. 2011. Quality control and preprocessing of metagenomic datasets. Bioinformatics 27:863-864. 10.1093/bioinformatics/btr026

See-Too WS, Chua KO, Lim YL, Chen JW, Convey P, Mohidin TBM, Yin WF, and Chan KG. 2017. Complete genome sequence of Planococcus donghaensis JH1(T), a pectin-degrading bacterium. Journal of Biotechnology 252:11-14. 10.1016/j.jbiotec.2017.05.005

Segata N, Izard J, Waldron L, Gevers D, Miropolsky L, Garrett WS, and Huttenhower C. 2011. Metagenomic biomarker discovery and explanation. Genome Biology 12. ARTN R6010.1186/gb-2011-12-6-r60

Sgroy V, Cassan F, Masciarelli O, Del Papa MF, Lagares A, and Luna V. 2009. Isolation and characterization of endophytic plant growth-promoting (PGPB) or stress homeostasis-regulating (PSHB) bacteria associated to the halophyte Prosopis strombulifera. Applied Microbiology and Biotechnology 85:371381. 10.1007/s00253-009-2116-3

Shange RS, Ankumah RO, Ibekwe AM, Zabawa R, and Dowd SE. 2012. Distinct Soil Bacterial Communities Revealed under a Diversely Managed Agroecosystem. Plos One 7. ARTN e4033810.1371/journal.pone.0040338

Shi SJ, O'Callaghan M, Jones EE, Richardson AE, Walter C, Stewart A, and Condron L. 2012. Investigation of organic anions in tree root exudates and rhizosphere microbial communities using in situ and destructive sampling techniques. Plant and Soil 359:149-163. 10.1007/s11104-012-1198-3

Siddikee MA, Chauhan PS, Anandham R, Han GH, and Sa T. 2010. Isolation, characterization, and use for plant growth promotion under salt stress, of ACC deaminase-producing halotolerant bacteria derived from coastal soil. Journal of Microbiology and Biotechnology 20:1577-1584. 10.4014/jmb.1007.07011

Smalla K, Wieland G, Buchner A, Zock A, Parzy J, Kaiser S, Roskot N, Heuer H, and Berg G. 2001. Bulk and rhizosphere soil bacterial communities studied by denaturing gradient gel electrophoresis: Plantdependent enrichment and seasonal shifts revealed. Applied and Environmental Microbiology 67:4742-4751. Doi 10.1128/Aem.67.10.4742-4751.2001

Song LY, Yang S, Liu HJ, and Xu J. 2017. Geographic and environmental sources of variation in bacterial community composition in a large-scale municipal landfill site in China. Applied Microbiology and Biotechnology 101:761-769. 10.1007/s00253-016-7917-6

Soussi A, Ferjani R, Marasco R, Guesmi A, Cherif H, Rolli E, Mapelli F, Ouzari HI, Daffonchio D, and Cherif 
715

716

717

718

719

720

721

722

723

724

725

726

727

728

729

730

731

732

733

734

735

736

737

738

739

740

741

742

743

744

745

746

747

748

749

750

751

752

753

754

755

A. 2016. Plant-associated microbiomes in arid lands: diversity, ecology and biotechnological potential. Plant and Soil 405:357-370. 10.1007/s11104-015-2650-y

Szymanska S, Plociniczak T, Piotrowska-Seget Z, and Hrynkiewicz K. 2016a. Endophytic and rhizosphere bacteria associated with the roots of the halophyte Salicornia europaea L. - community structure and metabolic potential. Microbiological Research 192:37-51. 10.1016/j.micres.2016.05.012

Szymanska S, Plociniczak T, Piotrowska-Seget Z, Zloch M, Ruppel S, and Hrynkiewicz K. 2016b. Metabolic potential and community structure of endophytic and rhizosphere bacteria associated with the roots of the halophyte Aster tripolium L. Microbiological Research 182:68-79. 10.1016/j.micres.2015.09.007

Takekawa JY, Miles AK, Schoellhamer DH, Athearn ND, Saiki MK, Duffy WD, Kleinschmidt S, Shellenbarger GG, and Jannusch CA. 2006. Trophic structure and avian communities across a salinity gradient in evaporation ponds of the San Francisco Bay estuary. Hydrobiologia 567:307-327. 10.1007/s10750-006-0061-z

Tang J, Zheng AP, Bromfield ESP, Zhu J, Li SC, Wang SQ, Deng QM, and Li P. 2011. 16S rRNA gene sequence analysis of halophilic and halotolerant bacteria isolated from a hypersaline pond in Sichuan, China. Annals of Microbiology 61:375-381. 10.1007/s13213-010-0137-x

Tian XY, and Zhang CS. 2017. Illumina-based analysis of endophytic and rhizosphere bacterial diversity of the coastal halophyte Messerschmidia sibirica. Frontiers in Microbiology 8. Artn 228810.3389/Fmicb.2017.02288

Tian YQ, and Gao LH. 2014. Bacterial diversity in the rhizosphere of cucumbers grown in soils covering a wide range of cucumber cropping histories and environmental conditions. Microbial Ecology 68:794806. 10.1007/s00248-014-0461-y

Tiwari S, Singh P, Tiwari R, Meena KK, Yandigeri M, Singh DP, and Arora DK. 2011. Salt-tolerant rhizobacteria-mediated induced tolerance in wheat (Triticum aestivum) and chemical diversity in rhizosphere enhance plant growth. Biology and Fertility of Soils 47:907-916. 10.1007/s00374-0110598-5

Vasquez EA, Glenn EP, Brown JJ, Guntenspergen GR, and Nelson SG. 2005. Salt tolerance underlies the cryptic invasion of North American salt marshes by an introduced haplotype of the common reed Phragmites australis (Poaceae). Marine Ecology Progress Series 298:1-8. DOI 10.3354/meps298001

Wang Q, Garrity GM, Tiedje JM, and Cole JR. 2007. Naive Bayesian classifier for rapid assignment of rRNA sequences into the new bacterial taxonomy. Applied and Environmental Microbiology 73:5261-5267. 10.1128/Aem.00062-07

Wang XL, Cui WJ, Feng XY, Zhong ZM, Li Y, Chen WX, Chen WF, Shao XM, and Tian CF. 2018. Rhizobia inhabiting nodules and rhizosphere soils of alfalfa: A strong selection of facultative microsymbionts. Soil Biology \& Biochemistry 116:340-350. 10.1016/j.soilbio.2017.10.033

Xi HY, Feng Q, Zhang L, Si JH, Chang ZQ, Yu TF, and Guo R. 2016. Effects of water and salinity on plant species composition and community succession in Ejina Desert Oasis, northwest China. Environmental Earth Sciences 75. Artn 13810.1007/S12665-015-4823-7

Yang GM. 1987. Photometric determination of organic matter in soil. Soils and Fertilizers:43-44.

Yang Y, Wang N, Guo XY, Zhang Y, and Ye BP. 2017. Comparative analysis of bacterial community structure in the rhizosphere of maize by high-throughput pyrosequencing. Plos One 12. ARTN e017842510.1371/journal.pone.0178425

PeerJ reviewing PDF | (2018:02:25925:2:1:NEW 24 Jul 2018) 
756

757

758

759

760

761

762

763

764

765

766

767

768

769

770
Zhang XN, Yang XD, and Lv GH. 2014. Diversity patterns and response mechanisms of desert plants to the soil environment along soil water ans salinity gradients. Acta Ecologica Sinica 36:3206-3215.

Zhao S, Zhou N, Zhao ZY, Zhang K, Wu GH, and Tian CY. 2016. Isolation of endophytic plant growthpromoting bacteria associated with the halophyte Salicornia europaea and evaluation of their promoting activity under salt stress. Current Microbiology 73:574-581. 10.1007/s00284-016-1096-7

Zhong ZP, Liu Y, Miao LL, Wang F, Chu LM, Wang JL, and Liu ZP. 2016. Prokaryotic community structure driven by salinity and ionic concentrations in plateau lakes of the Tibetan Plateau. Appl Environ Microbiol 82:1846-1858. 10.1128/AEM.03332-15

Zhou ML, Chen WM, Chen HY, and Wei GH. 2012. Draft genome sequence of Mesorhizobium alhagi CCNWXJ12-2(Tau), a novel salt-resistant species isolated from the desert of Northwestern China. Journal of Bacteriology 194:1261-1262. 10.1128/Jb.06635-11

Zhu YB, Tian JQ, Shi FY, Su L, Liu KK, Xiang MC, and Liu XZ. 2013. Rhizosphere bacterial communities associated with healthy and Heterodera glycines-infected soybean roots. European Journal of Soil Biology 58:32-37. 10.1016/j.ejsobi.2013.05.001 


\section{Figure 1}

Multiple comparisons of OTU richness (a) and $\alpha$-diversity (Shannon's index) (b) between rhizospheric and bulk soil bacterial communities, and among plant species within soil type.

Within boxes, horizontal bars indicate medians, while the tops and bottoms of boxes illustrate 75th and 25th quartiles, respectively. Small circles represent outliers in bulk samples. G, B, J, S, Z indicate bulk soil samples from Lycium ruthenicum, Limonium gmelinii, Halocnemum strobilaceum, Halostachys caspica, and Kalidium foliatum, respectively, while GQ, BX, JM, SM and $Z Z$ denote the corresponding rhizosphere samples from each species. Significance levels ( $p$ values) are provided for among-species comparisons within soil type (bulk versus rhizosphere), as well as between soil types.

a

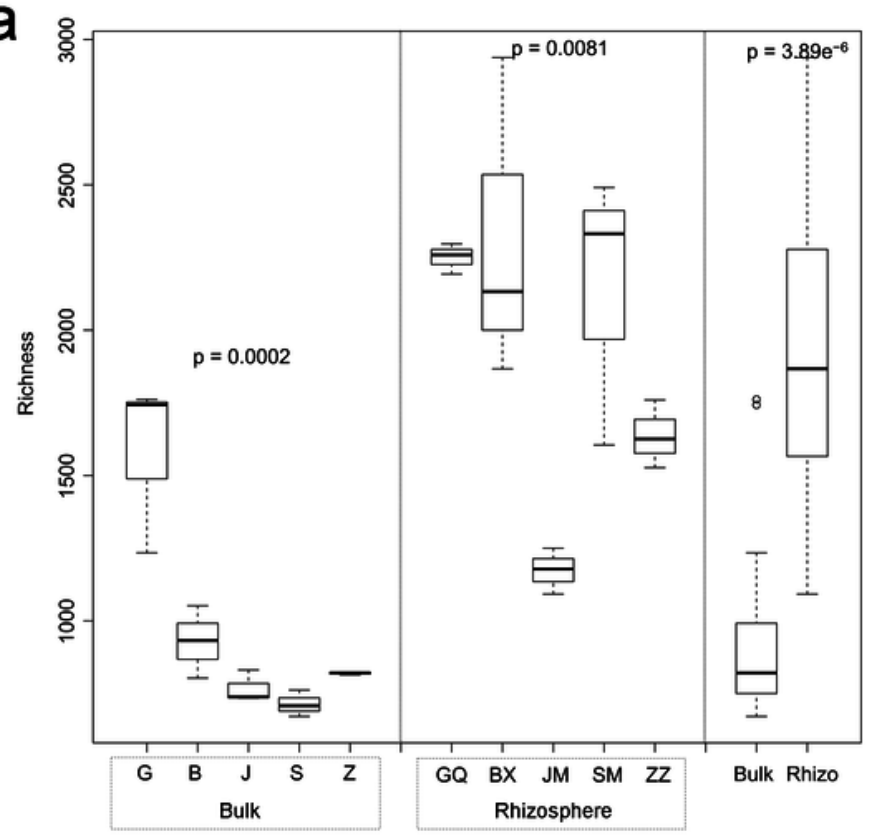

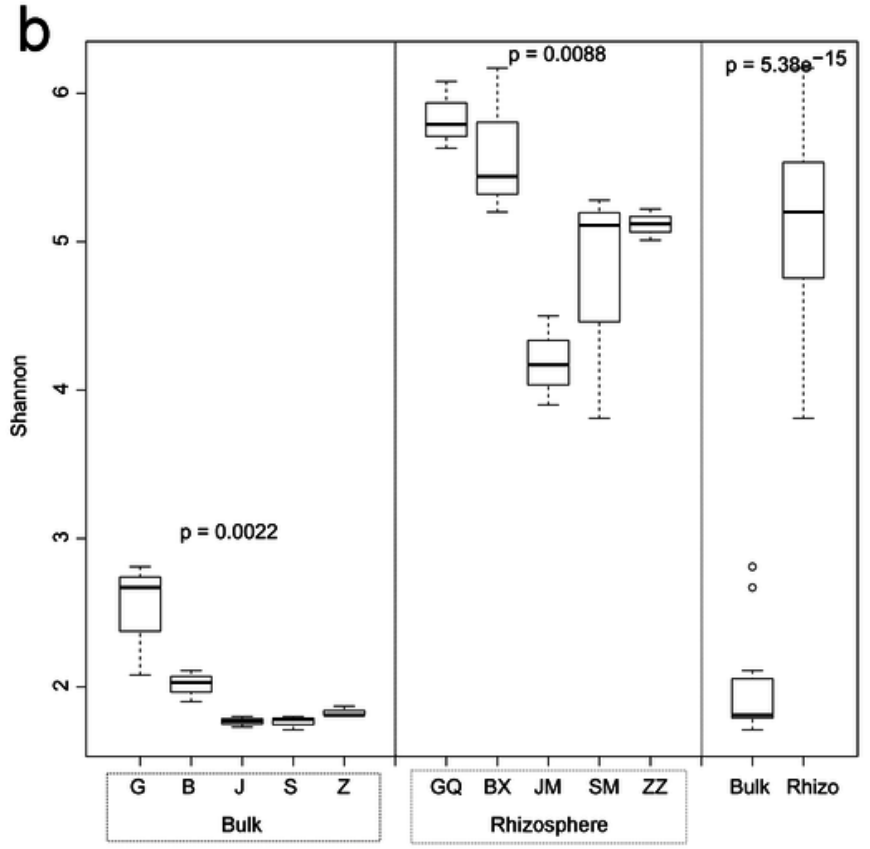


Figure 2

Venn diagram showing the OTUs shared among different samples.

a: rhizosphere samples, b: bulk soil samples. Information on OTU numbers is provided as follows: the total number of OTUs detected across all three replicates for each species (the number of OTUs shared among the three replicates). 


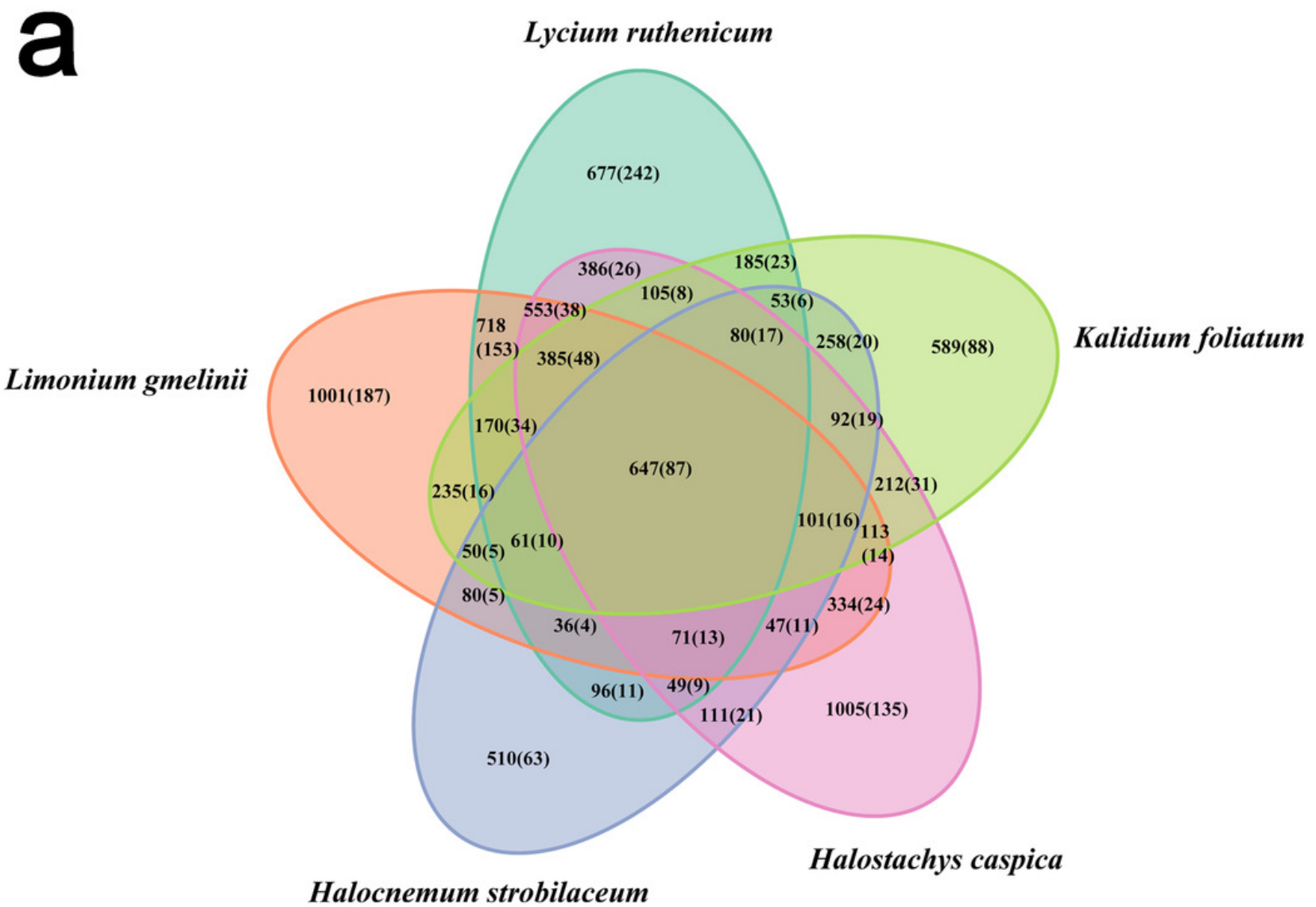

\section{Lycium ruthenicum}

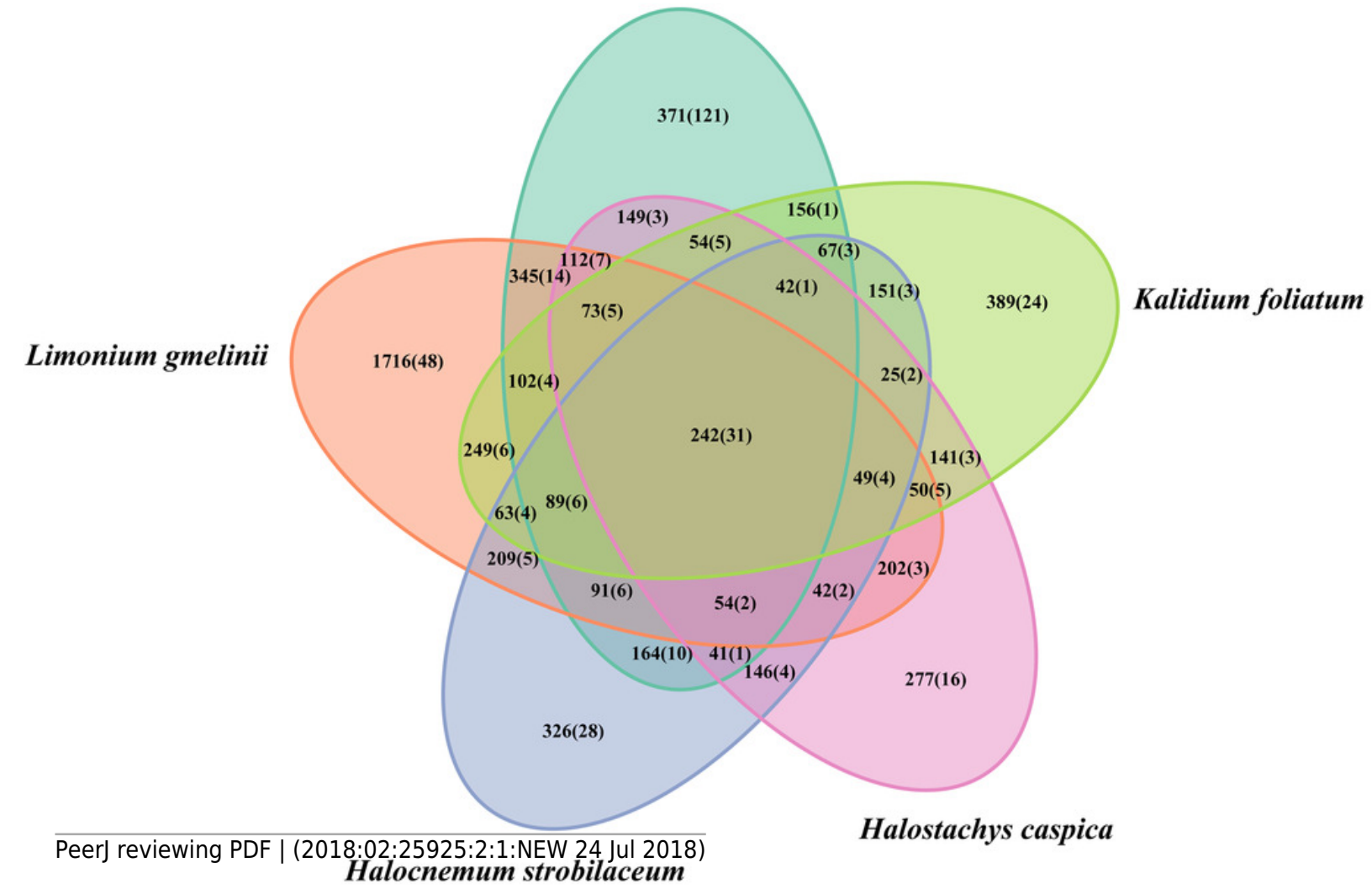


Figure 3

Diagrams depicting community composition and relative abundance at different taxonomic level.

a: phylum, b: class, c: genus. com/", 2.34 .
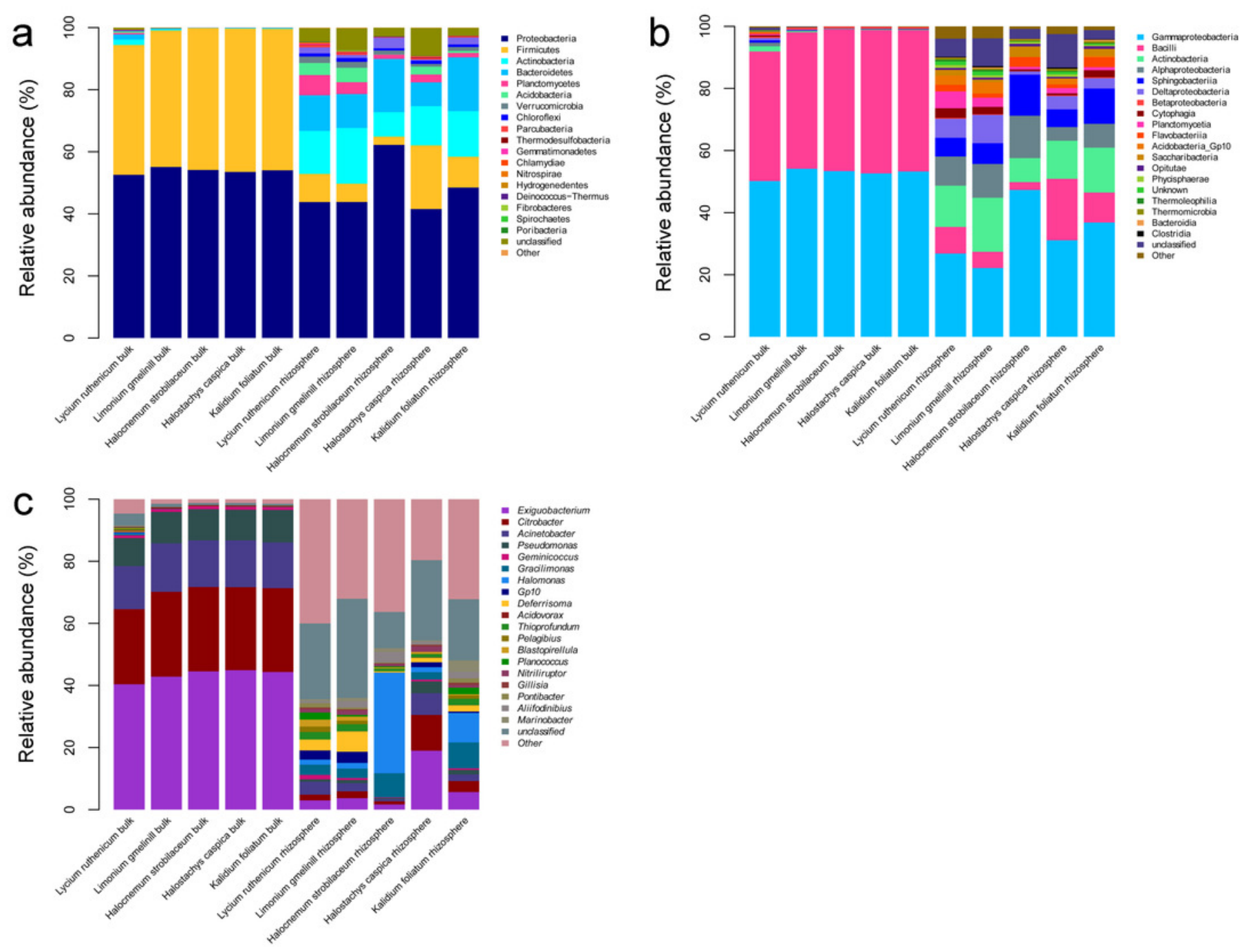


\section{Figure 4}

Principal coordinate analysis (PCOA) (a) and UPGMA clustering diagram (b) of soil samples

G, B, J, S and Z represent bulk soil samples from Lycium ruthenicum, Limonium gmelinii, Halocnemum strobilaceum, Halostachys caspica and Kalidium foliatum, respectively, while GQ, BX, JM, SM and ZZ represent rhizosphere samples associated with these species.

a

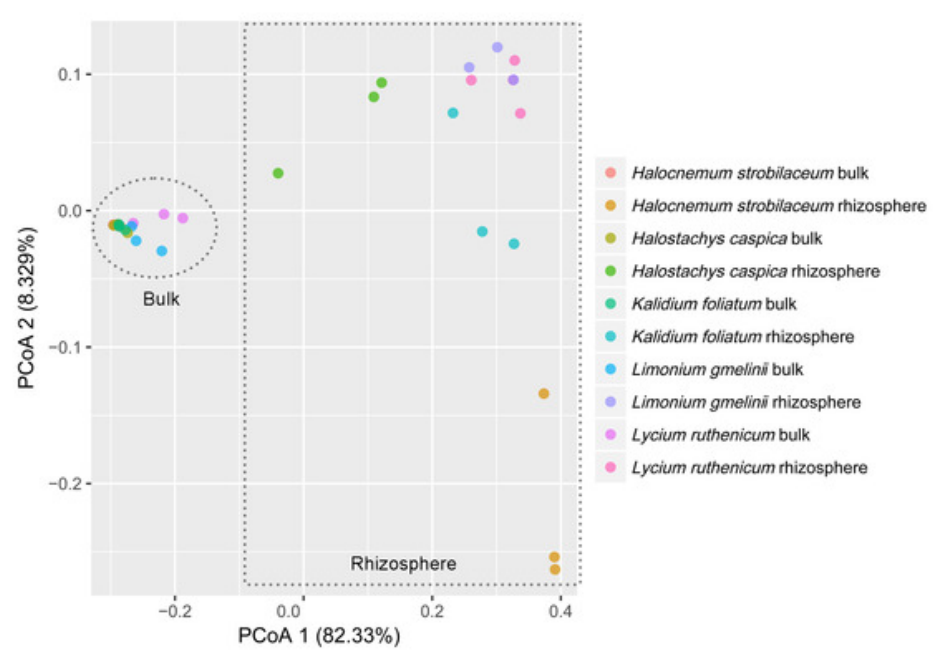

b

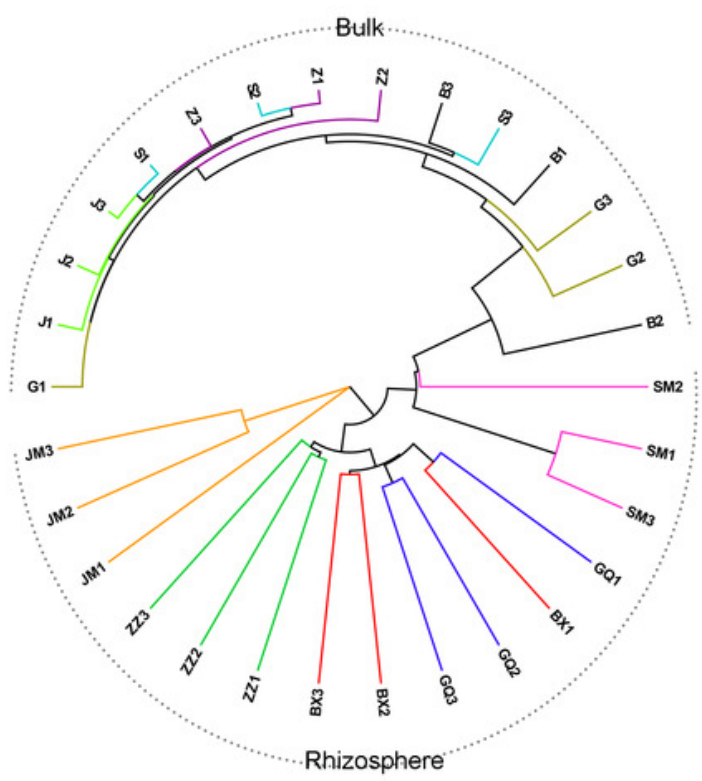




\section{Figure 5}

LEfSe analysis at multiple taxonomic levels comparing rhizobacterial community composition for five focal plant species.

(a) Cladogram illustrating the taxonomic groups explaining the most variation among rhizobacterial communities. Each ring represents a taxonomic level, with phylum (p), class (c), order (o), family (f) and genus (g) emanating from the center to the periphery. Each circle is a taxonomic unit found in the dataset, with circles or nodes shown in colors (other than yellow) indicating where a taxon was significantly more abundant. (b) Histogram of the LDA scores computed for groups with differential abundance among the rhizobacterial communities of the five plant species. 
a


a4: Mesorhizobium (g)

as: Phyllobacteriaceae (f)

a6: Bauldia $(\mathrm{g})$

a7: Rhizobiales incertae sedis $(f)$

a8: Albidovalum (g)

b0: Pelagibius (g)

bl: Rhodospirillaceae (f)

b4: 8 -proteobacteria incertae sedis (f)

b5: 8-proteobacteria incertae sedis (o) a9: Fodinicurvata (g)

a2: a-proteobacteria incertae sedis (f) b2: Rhodospirillales (o)

b3: Deferrisoma (g)

$b$

b
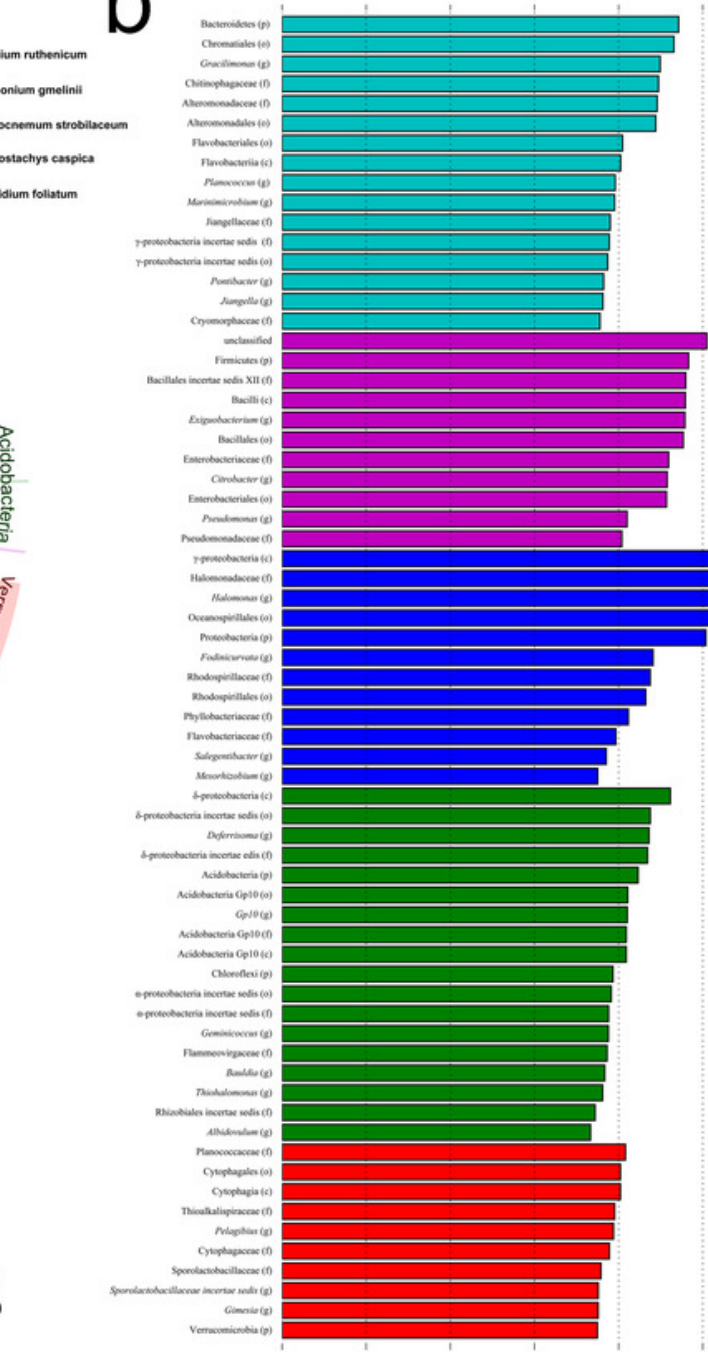

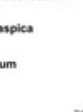

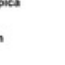




\section{Figure 6}

LEfSe analysis of bacterial community composition for bulk soil samples from four plant species.

(a) Cladogram illustrating the taxonomic groups that explain the most variation among the bacterial communities. (b) Histogram of the LDA scores computed for groups with differential abundance among the bacterial communities of the four plant species. Kalidium foliatumassociated communities did not form a separate group (from other plant species' associated communities) and, therefore, these are absent from the cladogram and histogram.
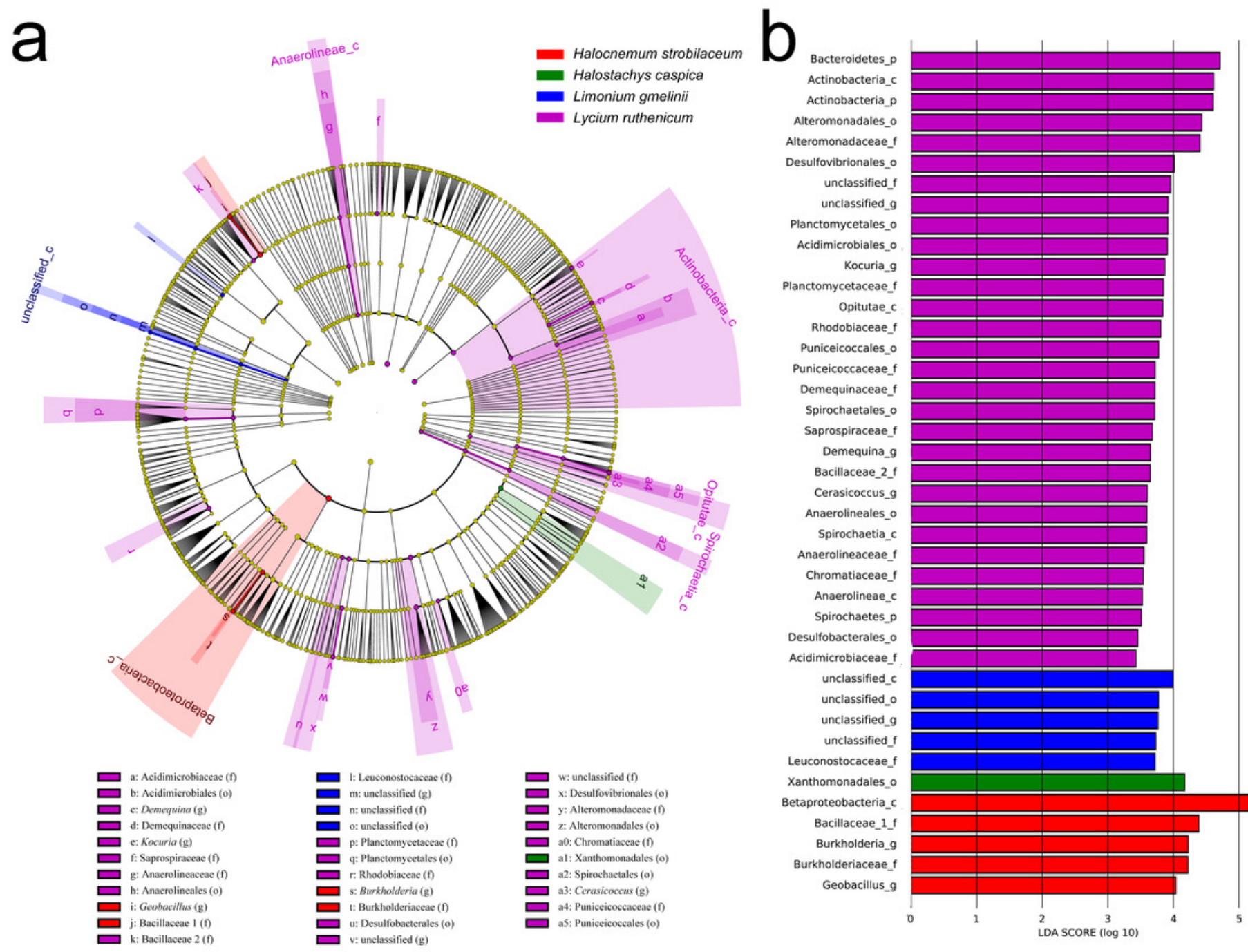


\section{Figure 7}

Canonical correspondence analysis (CCA) of the effect of soil properties on bacterial community structure in the rhizosphere (a) and bulk soil samples (b)

The soil properties are indicated with arrows, and include soil pH, electrical conductivity (EC), total organic carbon (TOC), soil organic matter (SOM), total nitrogen (TON), phosphorous (AP) and soil water content (SWC). The percentage of variation explained by each axis is provided. GQ, BX, JM, SM and ZZ represent rhizosphere samples associated with Lycium ruthenicum, Limonium gmelinii, Halocnemum strobilaceum, Halostachys caspica and Kalidium foliatum, respectively. G, B, J, S and Z represent bulk soil samples from Lycium ruthenicum, Limonium gmelinii, Halocnemum strobilaceum, Halostachys caspica and Kalidium foliatum, respectively.
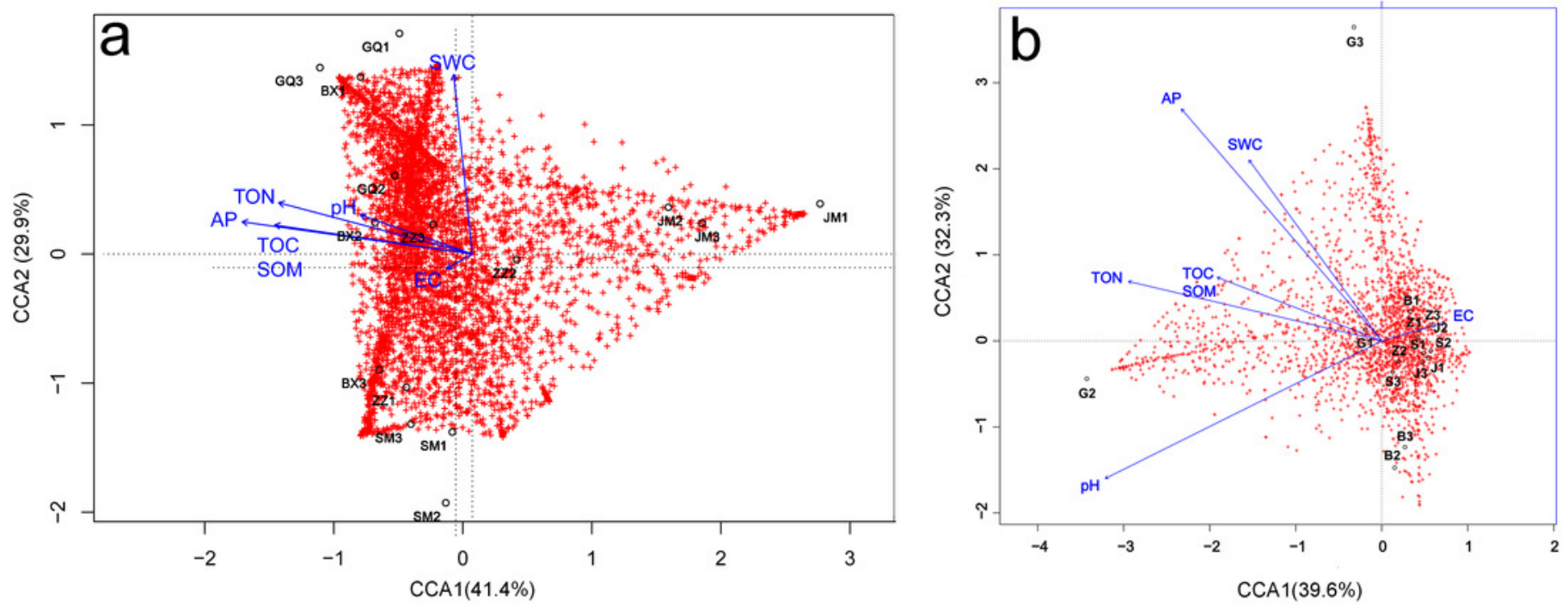


\section{Table 1 (on next page)}

Soil characteristics of bulk soil samples from five halophytes. 
2 Table 1 Soil characteristics of bulk soil samples from five halophytes.

\begin{tabular}{|c|c|c|c|c|c|c|c|}
\hline & $\begin{array}{l}\text { TOC } \\
(\mathrm{g} / \mathrm{kg}) \\
\end{array}$ & $\begin{array}{l}\text { SOM } \\
(\mathrm{g} / \mathrm{kg})\end{array}$ & $\begin{array}{l}\text { TON } \\
(\mathrm{g} / \mathrm{kg}) \\
\end{array}$ & $\begin{array}{l}\text { AP } \\
(\mathrm{g} / \mathrm{kg})\end{array}$ & $\mathrm{pH}$ & $\begin{array}{l}\mathrm{EC} \\
(\mathrm{mS} / \mathrm{cm})\end{array}$ & $\begin{array}{l}\text { SWC } \\
(\%)\end{array}$ \\
\hline Lycium ruthenicum & $9.14 \pm 3.43 \mathrm{a}$ & $15.75 \pm 5.92 \mathrm{a}$ & $0.58 \pm 0.24 \mathrm{a}$ & $0.89 \pm 0.15 a$ & $8.23 \pm 0.37$ & $5.56 \pm 1.26 b$ & $19.73 \pm 2.18 \mathrm{a}$ \\
\hline Limonium gmelinii & $10.78 \pm 1.60 \mathrm{a}$ & $18.59 \pm 2.77 \mathrm{a}$ & $0.60 \pm 0.10 \mathrm{a}$ & $0.80 \pm 0.08 \mathrm{a}$ & $8.33 \pm 0.24$ & $6.61 \pm 0.91 \mathrm{ab}$ & $17.02 \pm 3.51 \mathrm{a}$ \\
\hline Kalidium foliatum & $11.27 \pm 5.66 \mathrm{a}$ & $19.43 \pm 9.76 \mathrm{a}$ & $0.64 \pm 0.25 \mathrm{a}$ & $0.92 \pm 0.08 \mathrm{a}$ & $8.02 \pm 0.25$ & $5.65 \pm 0.53 b$ & $16.45 \pm 6.11 \mathrm{a}$ \\
\hline Halostachys caspica & $5.53 \pm 0.95 b$ & $9.53 \pm 1.63 b$ & $0.34 \pm 0.03 \mathrm{ab}$ & $0.82 \pm 0.06 \mathrm{a}$ & $8.05 \pm 0.16$ & $6.78 \pm 1.42 \mathrm{ab}$ & $10.42 \pm 2.57 b$ \\
\hline Halocnemum strobilaceum & $3.15 \pm 1.09 b$ & $5.43 \pm 1.88 b$ & $0.21 \pm 0.02 b$ & $0.62 \pm 0.06 b$ & $8.05 \pm 0.30$ & $7.14 \pm 1.46 \mathrm{a}$ & $17.71 \pm 3.16 \mathrm{a}$ \\
\hline mean & $8.05 \pm 4.15$ & $13.87 \pm 7.15$ & $0.48 \pm 0.23$ & $0.82 \pm 0.14$ & $8.14 \pm 0.27$ & $6.30 \pm 1.21$ & $16.40 \pm 4.57$ \\
\hline
\end{tabular}

3 Values are given as means ( \pm standard error) $(n=3)$.

4 Different letters indicate significant differences among five halophytes at $P<0.05$ level.

5 


\section{Table 2 (on next page)}

Adonis analysis of bacterial community composition for bulk soil and rhizosphere samples. 
1 Table 2 Adonis analysis of bacterial community composition for bulk soil and rhizosphere samples.

\begin{tabular}{llllll}
\hline & Lycium ruthenicum & Limonium gmelinii & Halocnemum strobilaceum & Halostachys caspica & Kalidium foliatum \\
\hline Lycium ruthenicum & & $0.323(0.3)$ & $0.399(0.199)$ & $0.319(0.289)$ & $0.367(0.089)$ \\
Limonium gmelinii & $0.324(0.108)$ & & $0.145(0.486)$ & $0.042(0.894)$ & $0.086(0.615)$ \\
Halocnemum strobilaceum & $0.697(0.126)$ & $0.718(0.098)$ & & $0.096(0.605)$ & $0.175(0.499)$ \\
Halostachys caspica & $0.528(0.104)$ & $0.513(0.11)$ & $0.750(0.104)$ & & $0.016(0.904)$ \\
Kalidium foliatum & $0.457(0.097)$ & $0.504(0.102)$ & $0.521(0.098)$ & $0.574(0.114)$ & \\
\hline
\end{tabular}

data was shown in format of $\mathrm{R}^{2}(P$ value); values below diagonal are for rhizosphere samples, and above diagonal for bulk samples. 


\section{Table 3(on next page)}

Pearson correlation coefficients among soil chemical properties, and between soil properties and community diversity. 
1 Table 3 Pearson correlation coefficients among soil chemical properties, and between soil properties and 2 community diversity.

\begin{tabular}{|c|c|c|c|c|c|c|c|c|}
\hline & TOC & TON & $\mathrm{AP}$ & SWC & $\mathrm{pH}$ & $\mathrm{EC}$ & OTU richness & Shannon index \\
\hline TOC & & & & & & & 0.446 & 0.484 \\
\hline TON & $0.970 * * *$ & & & & & & $0.549 *$ & $0.620 *$ \\
\hline AP & $0.728 * *$ & $0.761 * * *$ & & & & & $0.559 *$ & $0.609 *$ \\
\hline SWC & $0.479 *$ & $0.476^{*}$ & 0.137 & & & & 0.485 & 0.435 \\
\hline $\mathrm{pH}$ & 0.420 & 0.467 & 0.151 & 0.301 & & & 0.504 & 0.459 \\
\hline $\mathrm{EC}$ & -0.211 & -0.235 & -0.126 & -0.206 & 0.235 & & -0.093 & -0.054 \\
\hline
\end{tabular}

3 * indicates significance level, $* P<0.05, * * P<0.01, * * * P<0.001$.

4 EC: electrical conductivity, TOC: total organic carbon, SOM: soil organic matter, TON: total nitrogen, AP: 5 available phosphorous, SWC: soil water content. 